Check for updates

Cite this: J. Mater. Chem. A, 2017, 5 , 12216

Received 8th February 2017

Accepted 11th May 2017

DOI: 10.1039/c7ta01195d

rsc.li/materials-a

\section{Immobilization of copper complexes with $(1,10-$ phenanthrolinyl)phosphonates on titania supports for sustainable catalysis $\uparrow$}

\begin{abstract}
Alexander Mitrofanov, (D) ${ }^{\text {ab }}$ Stéphane Brandès, (D) ${ }^{a}$ Frédéric Herbst, (D) ${ }^{c}$ Séverinne Rigolet, (D) ${ }^{d}$ Alla Bessmertnykh-Lemeune (D) *a and Irina Beletskaya (D) *b

Different strategies for the immobilization of copper complexes with 1,10-phenanthroline (phen) using the phosphonate anchoring group were investigated to prepare robust and porous heterogeneous catalysts. Homoleptic and heteroleptic copper(I) complexes with phen bearing the bis(trimethylsiloxy) phosphoryl anchoring group (Pphen-Si) at different positions of the phen backbone were prepared and covalently incorporated into titania $\left(\mathrm{TiO}_{2}\right)$ xerogels by using the sol-gel process or grafted onto the surface of mesoporous $\mathrm{TiO}_{2}\left(S_{\mathrm{BET}}=650 \mathrm{~m}^{2} \mathrm{~g}^{-1}\right)$. Copper(I) bis(Pphen-Si) complexes were the only complexes that were successfully anchored onto the $\mathrm{TiO}_{2}$ surface because the heterogenization was often accompanied by the undesirable dissociation of copper complexes. Hybrid materials based on copper(I) chelates with one phen ligand were obtained following a two-step procedure involving the immobilization of Pphen-Si chelators and their successive complexation with copper(I) ions. Porous material, Cu/6b/SM/A, displaying a BET surface area of $243 \mathrm{~m}^{2} \mathrm{~g}^{-1}$ and bearing $0.57 \mathrm{mmol} \mathrm{g}^{-1}$ of the complex was synthesized according to this approach. Excellent catalytic performance of the reusable $\mathrm{Cu} / 6 \mathrm{~b} / \mathrm{SM} / \mathrm{A}$ material in the Sonogashira-type coupling and the Huisgen 1,3-dipolar cycloaddition was also demonstrated. This solid represents the first example of mesoporous $\mathrm{TiO}_{2}$-supported transition metal catalysts.
\end{abstract}

\section{Introduction}

Copper catalysts could replace precious metal complexes in many industrial processes involved in pharmaceutical, dye and polymer productions. ${ }^{1-3}$ This is of major importance in view of societal concerns relating to environmental and sustainable chemistry. In the last two decades, significant improvements in homogeneous Cu-catalysed $\mathrm{C}-\mathrm{C}^{4-7}$ and $\mathrm{C}-\mathrm{Het}$ (Het $=\mathrm{O}, \mathrm{S}, \mathrm{Se}, \mathrm{N}$, $\mathrm{P})^{\mathbf{6}, \mathbf{8}}$ cross-coupling reactions, additions to unsaturated $\mathrm{C}-\mathrm{C}$ bonds, ${ }^{9}$ Huisgen 1,3-dipolar cycloaddition, ${ }^{\mathbf{1 0}}$ and other organic transformations $\mathrm{s}^{\mathbf{2 , 9 , 1 1 - 1 5}}$ were reported. Homogeneous catalysts are well suited for increasing the reaction scope and fine tuning the reaction rate and its selectivity. However, the separation of organic products from toxic copper compounds are particularly troublesome $\mathrm{e}^{\mathbf{1 6}, \mathbf{1 7}}$ due to the exceptional coordination properties

Institut de Chimie Moléculaire de l'Université de Bourgogne (ICMUB), UMR CNRS 6302, 9 Av. Alain Savary, 21078 Dijon, France.E-mail: Alla.Lemeune@u-bourgogne.fr ${ }^{b}$ Department of Chemistry, Lomonosov Moscow State University, Leninskie Gory, GSP1, Moscow 119991, Russia. E-mail: beletska@org.chem.msu.ru

${ }^{\circ}$ Laboratoire Interdisciplinaire Carnot de Bourgogne, UMR CNRS 6303, 9 Av. Alain Savary, 21078 Dijon, France

${ }^{d}$ Institut de Science des Matériaux de Mulhouse, Université de Haute-Alsace, UMR CNRS 7361, 15 rue Jean Starcky, Mulhouse, 68057, France

$\dagger$ Electronic supplementary information (ESI) available. See DOI: $10.1039 / \mathrm{c} 7 \mathrm{ta0} 01195 \mathrm{~d}$ of this metal, which avidly bind a huge range of organic molecules containing oxygen and nitrogen donor sites. To solve this problem and recover the catalyst, several strategies were explored. It was reported that copper nanoparticles and coppermodified dendrimers can occasionally replace homogeneous catalysts. ${ }^{18,19}$ However, their use in industrial processes is also hampered by the difficult purification of products from catalysts. Consequently, copper nanoparticles, salts and oxides were immobilized onto insoluble supports, either organic (polystyrene $^{20,21}$ polyaniline ${ }^{22}$ and cellulose $^{23}$ ) or inorganic (zeolites, ${ }^{24}$ hydrotalcite, ${ }^{25,26}$ hydroapatites, ${ }^{27}$ fluorapatites, ${ }^{28}$ silica, ${ }^{20,29,30}$ alumina $^{31-34}$ and others ${ }^{35-38}$ ). In these materials, copper ions or nanoparticles are weakly bonded to the solid supports bearing hydroxy, sulfonate or amine coordinating sites. These catalysts benefit from a spatial separation of catalytic species and can be easily recovered, but their stability is quite low. As a result, copper leaching is observed that leads to metal contamination of products and decrease in the catalytic activity of the recovered solids.

Another promising approach to robust catalytic materials is a direct immobilization of relevant copper complexes onto solid supports such as silicas, ${ }^{21,39-41}$ zeolites, ${ }^{42}$ metal-organic frameworks (MOFs) ${ }^{43}$ or graphene. ${ }^{\mathbf{4 4}}$ For instance, heterogenized copper $N, N$ - and $N, O$-chelates $(\mathrm{Cu} / \mathrm{L})$ were applied as catalysts in Huisgen cycloaddition, ${ }^{\mathbf{2 1 , 4 1 , 4 5}}$ Mannich three-component 
coupling reaction, ${ }^{\mathbf{4 6}}$ Sonogashira-type coupling, ${ }^{47}$ Ullmann-type arylation of amines, ${ }^{48}$ oxidative carbonylation of methano ${ }^{39}$ and other organic transformations. Surprisingly, catalyst leaching is difficult to control even for these materials. As a result, it is still a common industrial practice to avoid, whenever possible, the use of copper catalysts, in particular during the later steps of the synthesis of complex molecules in pharmaceutical and agrochemical industries. There is thus a need to develop more efficient immobilization strategies for the heterogenization of copper chelates.

The choice of the solid support is a key point for efficient catalyst immobilization. Inorganic supports offer various inherent advantages over organic and biopolymer supports. They are insoluble in common organic solvents and water, do not swell, and display high structural, thermal, mechanical and chemical stability. The rigid structure of these supports allows for a spatial separation of catalytic centres. Recent investigations of hybrid organic-inorganic materials based on phosphonates revealed that metal oxides or polymeric phosphonate networks can be used as a solid support for heterogenization of transition metal complexes. ${ }^{\mathbf{4 9}-52}$ Among them, $\mathrm{TiO}_{2}$ is particularly interesting because the resulting molecular materials are cost-effective and display exceptional thermal and chemical stability stemming from the robustness of $\mathrm{Ti}-\mathrm{O}(\mathrm{P})$ and $\mathrm{P}-\mathrm{C}$ bonds. Several strategies are currently available for immobilization of phosphonates onto $\mathrm{TiO}_{2}$ supports including sol-gel (SG) processes and surface modification (SM) reactions. ${ }^{53-55}$
Examples of $\mathrm{TiO}_{2}$-supported transition metal catalysts are still limited to a few reports. Immobilization of palladium complexes with phosphine ligands bearing phosphonate anchoring groups on $\mathrm{TiO}_{2}$ matrices was carefully studied but all obtained materials were inefficient in the Sonogashira coupling reaction. ${ }^{56} \mathrm{Ru}(\mathrm{II})$ and $\operatorname{Ir}(\mathrm{I})$ complexes with bipyridine were incorporated into $\mathrm{TiO}_{2}$ matrices in order to prepare heterogeneous catalysts for reduction of aromatic and unsaturated ketones. ${ }^{53,57}$ Under appropriate conditions, these solids catalysed heterogeneous hydrogenation with practically useful chemoselectivity. A titania-supported Co(I) complex prepared by using the SG method was found to be an efficient catalyst for the hydroformylation of alkenes in contrast to a relevant homogeneous complex. ${ }^{58}$ It has to be noted that all reported hybrid materials based on titania were non-porous and displayed low specific surface areas $\left(<100 \mathrm{~m}^{2} \mathrm{~g}^{-1}\right)$. This is a serious drawback for their catalytic performance.

In the present work, we report the heterogenization of copper complexes with phen ligands bearing the phosphonate anchoring group using titania matrices. This approach to the immobilization of copper catalysts combines several potential advantages including the thermodynamic stability of copper chelates with phen ligands, their catalytic efficiency and versatility, the strong covalent linkage of phosphonates to $\mathrm{TiO}_{2}$ networks and excellent mechanical, thermal and chemical properties of titania, which is widely used in industry as a support for inorganic catalysts. In particular, we were

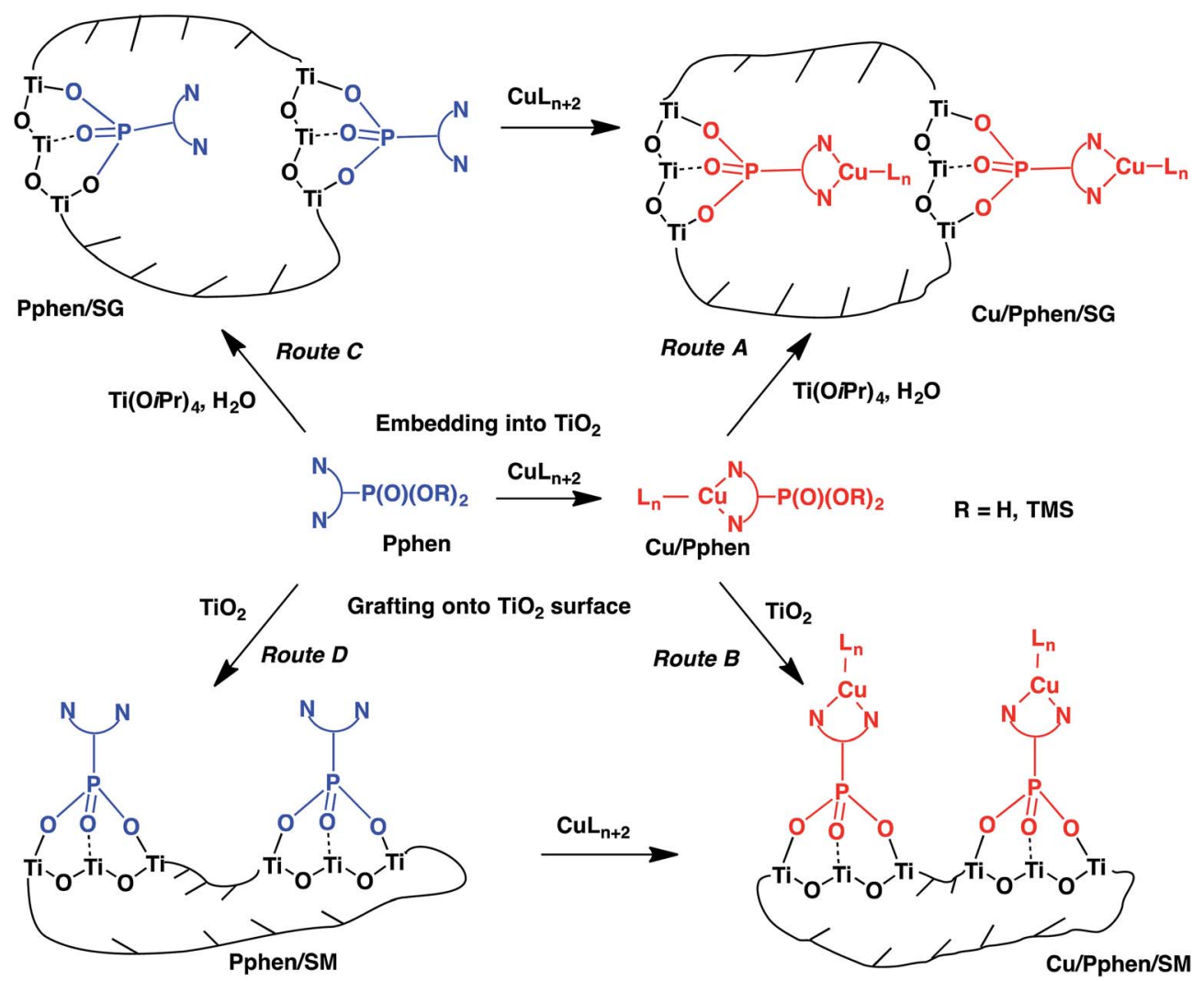

Scheme 1 Schematic representation of the immobilization of copper complexes with phen ligands according to the SG process (routes A and C) and the SM reaction (routes $B$ and $D$ ). 

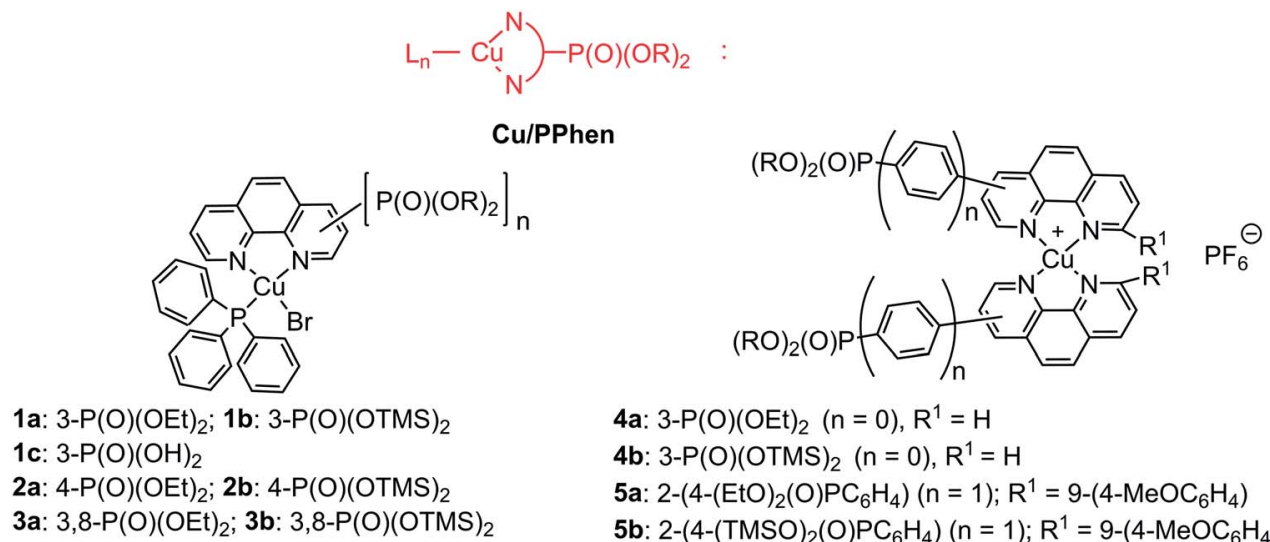

4a: 3-P(O)(OEt) $)_{2}(n=0), R^{1}=H$

4b: 3-P(O)(OTMS $)_{2}(n=0), R^{1}=H$

5a: $2-\left(4-(\mathrm{EtO})_{2}(\mathrm{O}) \mathrm{PC}_{6} \mathrm{H}_{4}\right)(\mathrm{n}=1) ; \mathrm{R}^{1}=9-\left(4-\mathrm{MeOC}_{6} \mathrm{H}_{4}\right)$

5b: $2-\left(4-(T M S O)_{2}(O) \mathrm{PC}_{6} \mathrm{H}_{4}\right)(\mathrm{n}=1) ; \mathrm{R}^{1}=9-\left(4-\mathrm{MeOC}_{6} \mathrm{H}_{4}\right)$

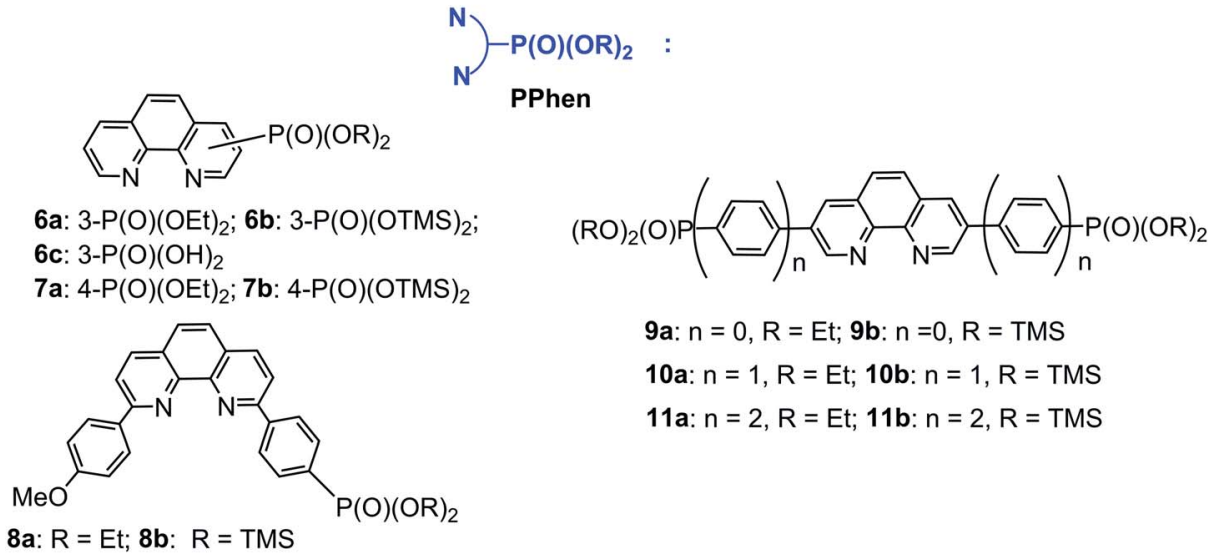

Fig. 1 Structures of Pphen ligands and Cu/Pphen complexes.

interested to control the porosity of the materials and prepare cost-effective solid catalysts with surface characteristics that are relatively close to those of mesoporous materials commonly used as heterogenized catalysts such as functionalized ordered silicas. In this regard, the immobilization of phen ligands functionalized by the phosphonate group (Pphen) and their copper(I) complexes (Cu/Pphen) was investigated in detail. First, $\mathbf{P p h e n} / \mathbf{S G}$ and $\mathbf{C u} / \mathbf{P p h e n} / \mathbf{S G}$ materials were prepared by reacting Pphen ligands or their complexes with titanium isopropoxide ( $\mathrm{Ti}(\mathrm{O} i \mathrm{Pr})_{4}$ ) according to the SG process (Scheme 1, routes A and C, Fig. 1). Alternatively, these ligands and complexes were grafted onto the surface of mesoporous titanium oxide $\left(S_{\mathrm{BET}}=\right.$ $650 \mathrm{~m}^{2} \mathrm{~g}^{-1}$ ) yielding Pphen/SM and $\mathbf{C u} / \mathbf{P p h e n} / \mathbf{S M}$ materials (Scheme 1, routes B and D, Fig. 1). Moreover, the complexation of copper ions with Pphen/SM solids was explored to prepare heterogenized chelates. The structural characteristics of hybrid materials and the integrity of the immobilized molecules were investigated by different physicochemical methods, including elemental analysis, infrared (FTIR) spectroscopy, nitrogen sorption isotherms, EDX spectrometry, scanning electron microscopy (SEM), transmission electron microscopy (TEM) and solid-state NMR. Finally, the catalytic performance of the most porous material $\mathbf{C u} / \mathbf{6 b} / \mathbf{S M} / \mathbf{A}$ was examined in the Sonogashira-type and Huisgen cycloaddition reactions. These studies demonstrated that $\mathbf{C u} / \mathbf{6 b} / \mathbf{S M} / \mathbf{A}$ is stable in the presence of strong bases like triethylamine and cesium carbonate and efficient as a catalyst for both reactions. This solid catalyst can be readily recovered and reused up to 10 times without loss of activity. To the best of our knowledge, this is the first example of mesoporous titania-supported transition metal catalysts.

\section{Experimental}

Unless otherwise noted, all chemicals and starting materials were obtained commercially from Acros ${ }^{\circledR}$ or Aldrich ${ }^{\circledR}$ and used without further purification. The complex $\mathrm{Cu}\left(\mathrm{PPh}_{3}\right)_{3} \mathrm{Br},{ }^{59}$ 3,8dibromo-1,10-phenanthroline, ${ }^{60}$ 2-chloro-9-(4-methoxyphenyl)1,10-phenanthroline, ${ }^{61} 4$-(diethoxyphosphoryl)phenylboronic acid pinacol ester ${ }^{62}$ and 4-(diethoxyphosphorylphenyl)-4'-phenylboronic acid pinacol ester ${ }^{62}$ were prepared according to literature methods. Mesoporous $\mathrm{TiO}_{2}$ was synthesized from $\mathrm{Ti}(\mathrm{O} i \mathrm{Pr})_{4}$ by the sol-gel process in the presence of a limited amount of water $(20$ equiv.) in THF (see the ESI $\dagger$ ). ${ }^{63}$ The empirical formula of hydrated $\mathrm{TiO}_{2}\left(\left(\mathrm{TiO}_{x}(\mathrm{OH})_{4-2 x}\right) \cdot m\left(\mathrm{H}_{2} \mathrm{O}\right) \cdot n(\mathrm{iPrOH}), x=1.6-1.8 ; m=0.1-0.4 ;\right.$ $n=0.1-0.2)$ was calculated based on the elemental analysis of the xerogel dried at $80^{\circ} \mathrm{C}$ under reduced pressure for $12 \mathrm{~h}$.

Phenanthrolinylphosphonates $6 \mathrm{a}, 7 \mathrm{a}$ and $9 \mathrm{9a},{ }^{64}$ heteroleptic copper(I) complexes $\mathrm{Cu}(\mathbf{P p h e n})\left(\mathrm{PPh}_{3}\right) \mathrm{Br} \quad(\mathbf{1 a}-\mathbf{3 a})^{65}$ and the homoleptic complex $\left[\mathrm{Cu}(\mathbf{P p h e n})_{2}\right] \mathrm{PF}_{6} \quad(\mathbf{4 a})^{65}$ were obtained according to our previous reports.

Analytical thin-layer chromatography (TLC) was carried out using Merck silica gel 60 plates (precoated sheets, $0.2 \mathrm{~mm}$ thick, 
with the fluorescence indicator F254). Column chromatography purification was carried out on silica gel (silica 60, 63-200 $\mu \mathrm{m}$, Aldrich) and neutral alumina (aluminium oxide 90, 63-200 $\mu \mathrm{m}$, Merck). Centrifugation was performed at $6000 \mathrm{rpm}$ for $5 \mathrm{~min}$. Catalytic reactions were carried out using Carousel 12 Plus equipment for parallel synthesis (Radleys).

${ }^{1} \mathrm{H},{ }^{31} \mathrm{P}$ and ${ }^{13} \mathrm{C}$ NMR spectra were acquired either on a Bruker Avance III $500 \mathrm{MHz}$ or a Bruker Avance III Nanobay 300 $\mathrm{MHz}$ spectrometer. Chemical shifts are expressed in parts per million (ppm) and referenced to residual non-deuterated solvent signals. ${ }^{66,67}$ The coupling constants are expressed in units of frequency $(\mathrm{Hz})$. The unambiguous assignment of signals in ${ }^{1} \mathrm{H}$ and ${ }^{13} \mathrm{C}$ NMR spectra was performed using gradient-enhanced COSY, HMQC and NOESY correlation experiments. MALDI-TOF mass-spectra were obtained on a Bruker Ultraflex II LRF 2000 mass-spectrometer in positive ion mode with a dithranol matrix. Microanalyses (CHN) were performed on a Thermo Finnigan Flash 1112 analyser. $\mathrm{Cu}, \mathrm{P}$ and Ti elemental analyses were performed with inductively coupled plasma optical emission spectrometers ICP-OES (DUO) ICAP 7400. FTIR spectra were registered on FT-IR Nexus (Nicolet) and Bruker Vector 22 spectrophotometers. Micro-ATR accessory (Pike) was used in order to obtain FTIR spectra of polycrystalline solid complexes. Thermogravimetric (TGA) measurements were performed on a Netzsch STA 409 PC Luxx analyser. Samples were purged in an $\mathrm{N}_{2}\left(30 \mathrm{~mL} \mathrm{~min}{ }^{-1}\right) / \mathrm{O}_{2}\left(10 \mathrm{~mL} \mathrm{~min}^{-1}\right)$ stream during analysis and heated to $1000^{\circ} \mathrm{C}$ in alumina crucibles with a heating rate of $10 \mathrm{~K} \mathrm{~min}^{-1}$. Powder X-ray diffraction experiments were performed on an Empyrean diffractometer from the PANalytical company in the range $3^{\circ}<2 \theta<50^{\circ}$. Uncrushed samples (few milligrams) were placed between two Mylar sheets and the analysis was performed in transmission mode using a focusing X-ray mirror equipped with fixed divergent and antiscattering slits (aperture $0.5^{\circ}$ ) and 0.02 rad Soller slits. Data collection was performed with a copper anticathode X-ray tube $\left(\mathrm{Cu} \mathrm{K} \alpha_{1}=1.54060 \AA / \mathrm{Cu} \mathrm{K} \alpha_{2}=1.54443 \AA\right)$ and with a X'Celerator detector equipped with an anti-scattering slit of $5 \mathrm{~mm}$. Accurate mass measurements (HRMS) were recorded on a Thermo LTQ Orbitrap XL apparatus equipped with an electrospray ionisation (ESI) source. Nitrogen adsorption-desorption isotherms were measured with a Micromeritics ASAP 2010 or 2020 analyser at $77 \mathrm{~K}$ with samples outgassed at $393 \mathrm{~K}$ under reduced pressure $\left(10^{-5}\right.$ torr $)$ for at least $6 \mathrm{~h}$. Specific surface areas were calculated by the BET method. ${ }^{68}$ Mesopore characterizations were performed by the Barrett-Joyner-Halenda method. ${ }^{69}$ Diffuse reflectance spectra were recorded in the solid state at room temperature on an Agilent Carry 5000 UV-Vis-NIR spectrometer. Continuous wave (CW) EPR spectra of solid samples were recorded on a Bruker ELEXSYS 500. The instrument was equipped with a $4122 \mathrm{SHQE} / 0405 \mathrm{X}$-band resonant cavity operating at $9.43 \mathrm{GHz}$, a X-band high power dual gun-oscillator bridge, and a quartz cryostat cooled at $100 \mathrm{~K}$ with a stream of nitrogen. The temperature was regulated with an ER 4131VT accessory. All apparatus as well as the data acquisition were controlled using Xepr software. The magnetic field was swept from 250 to $360 \mathrm{mT}$ through 2048 points. Spectra were recorded at $6 \mathrm{~mW}$ power, $100 \mathrm{kHz}$ frequency modulation, $0.5 \mathrm{mT}$ modulation amplitude, $10 \mathrm{~ms}$ time constant and $40 \mathrm{~ms}$ conversion time. The ${ }^{31} \mathrm{P}$ solid-state NMR experiment was performed at room temperature on a Bruker Avance II 400 spectrometer operating at $B_{0}=9.4 \mathrm{~T}$ equipped with a Bruker double channel $4 \mathrm{~mm}$ probe at a Larmor frequency of $161.99 \mathrm{MHz}$. The spectrum was recorded with a $\pi / 2$ pulse duration of $3.5 \mu$ s and a recycling delay of $60 \mathrm{~s}$ at a spinning frequency of $14 \mathrm{kHz} .{ }^{31} \mathrm{P}$ spin lattice relaxation times $\left(T_{1}\right)$ were measured with the saturation-recovery pulse sequence. The ${ }^{31} \mathrm{P}$ spectrum was referenced to $\mathrm{H}_{3} \mathrm{PO}_{4}$ ( $85 \%$ in water). Deconvolutions of the spectrum were performed using Dmfit software (http:// nmr.cemhti.cnrs-orleans.fr/dmfit/) with Gaussian/Lorentzian functions. Field-emission scanning electron microscopy (FESEM) was realized using a JEOL JSM 7600F instrument located in the ARCEN analysis centre of the University of Bourgogne (Dijon). Images were obtained using GentleBeamHigh SEM mode. Transmission electron microscopy (TEM) analyses were conducted using a JEOL JEM-2100F microscope operating at $200 \mathrm{kV}$ and located in the ARCEN analysis centre of the University of Bourgogne (Dijon). EDX spectrometry in STEM and TEM mode was used for chemical mapping and qualitative elemental analysis using a Bruker XFlash Detector 5030 spectrometer fitted on the JEM-2100F microscope.

All measurements except SEM and TEM imaging and solid state NMR were performed at the "Pôle Chimie Moléculaire", the technological platform for chemical analysis and molecular synthesis (http://www.wpcm.fr) which relies on the Institute of Molecular Chemistry of University of Burgundy and Welience $^{\mathrm{TM}}$, a Burgundy University private subsidiary.

\section{Synthesis of (1,10-phenanthrolinyl)phosphonates and complex 5a}

Diethyl (4-(9-(4-methoxyphenyl)-1,10-phenanthrolin-2-yl) phenyl)phosphonate (8a). A mixture of 2-chloro-9-(4methoxyphenyl)-1,10-phenanthroline $(160 \mathrm{mg}, 0.5 \mathrm{mmol})$, 4(diethoxyphosphoryl)phenylboronic acid pinacol ester $(187 \mathrm{mg}$, $0.55 \mathrm{mmol}), \mathrm{Pd}(\mathrm{dppf}) \mathrm{Cl}_{2}(20.4 \mathrm{mg}, 0.025 \mathrm{mmol})$ and $\mathrm{Cs}_{2} \mathrm{CO}_{3}$ $(815 \mathrm{mg}, 2.5 \mathrm{mmol})$ in dioxane was stirred for $3 \mathrm{~h}$ at reflux under Ar. The mixture was filtered and concentrated under reduced pressure. The residue was purified by column chromatography on silica gel (eluent $\mathrm{CH}_{2} \mathrm{Cl}_{2} / \mathrm{MeOH}\left(0-1 \% \mathrm{MeOH}\right.$ in $\left.\mathrm{CH}_{2} \mathrm{Cl}_{2}\right)$ ). Beige solid. Yield 70\% (174 mg). $\nu_{\max } / \mathrm{cm}^{-1} 2982(\mathrm{CH}), 2937$ $(\mathrm{CH}), 2905(\mathrm{CH}), 1602,1587,1578,1544,1488,1441,1421,1392$, 1362, 1300, $1246(\mathrm{P}=\mathrm{O}), 1174,1133,1113,1095,1016$ (POC), 958 (POC), 891, 837, 792, 780, 746. $\delta_{\mathrm{H}}\left(300 \mathrm{MHz}, \mathrm{CDCl}_{3}, 300 \mathrm{~K}\right)$ $1.38\left(\mathrm{t},{ }^{3} J_{\mathrm{H}, \mathrm{H}} 7.1,6 \mathrm{H}, \mathrm{Me}\right), 3.95(\mathrm{~s}, 3 \mathrm{H}, \mathrm{OMe}), 4.19\left(\mathrm{~m}, 4 \mathrm{H}, \mathrm{CH}_{2}\right)$, $7.14\left(\mathrm{~d},{ }^{3} J_{\mathrm{H}, \mathrm{H}} 8.8,2 \mathrm{H}, m-\mathrm{H}\right), 7.79$ (AB-system, $J_{\mathrm{AB}} 8.7,2 \mathrm{H}, 5,6-\mathrm{H}$ ), $8.06\left(\mathrm{dd},{ }^{3} \mathrm{~J}_{\mathrm{H}, \mathrm{P}} 13.0,{ }^{3} \mathrm{~J}_{\mathrm{H}, \mathrm{H}} 8.3,2 \mathrm{H}, m-\mathrm{H}\right), 8.13\left(\mathrm{~d},{ }^{3} J_{\mathrm{H}, \mathrm{H}} 8.7,1 \mathrm{H}, 8-\right.$ $\mathrm{H}), 8.18\left(\mathrm{~d},{ }^{3} J_{\mathrm{H}, \mathrm{H}} 8.7,1 \mathrm{H}, 3-\mathrm{H}\right), 8.30\left(\mathrm{~d},{ }^{3} J_{\mathrm{H}, \mathrm{H}} 8.7,1 \mathrm{H}, 7-\mathrm{H}\right), 8.37$ $\left(\mathrm{d},{ }^{3} J_{\mathrm{H}, \mathrm{H}} 8.7,1 \mathrm{H}, 4-\mathrm{H}\right), 8.45\left(\mathrm{~d},{ }^{3} J_{\mathrm{H}, \mathrm{H}} 8.8,2 \mathrm{H}, o-\mathrm{H}\right), 8.57\left(\mathrm{dd},{ }^{3} J_{\mathrm{H}, \mathrm{H}}\right.$ $\left.8.3,{ }^{4} J_{\mathrm{H}, \mathrm{P}} 3.9,2 \mathrm{H}, o-\mathrm{H}\right) . \delta_{\mathrm{C}}\left(125 \mathrm{MHz}, \mathrm{CDCl}_{3}, 300 \mathrm{~K}\right) 16.4\left(\mathrm{~d},{ }^{3} J_{\mathrm{C}, \mathrm{P}}\right.$ 6, 2C, Me), 55.4 (1C, OMe), $62.2\left(\mathrm{~d},{ }^{2} J_{\mathrm{C}, \mathrm{P}} 5,2 \mathrm{C}, \mathrm{OCH}_{2}\right), 114.3(2 \mathrm{C}$, $m$-C), 119.6 (1C, 8-C), 120.0 (1C, 3-C), 125.4 (1C, 6-C), 126.7 (1C, 5-C), 127.5 (1C, 4a or 6a-C), 127.7 (d, $\left.{ }^{3} J_{\mathrm{C}, \mathrm{P}} 15,2 \mathrm{C}, o-\mathrm{C}\right), 128.3$ (1C, $4 \mathrm{a}$ or $6 \mathrm{a}-\mathrm{C}), 128.8$ (d, ${ }^{1} J_{\mathrm{C}, \mathrm{P}} 187,1 \mathrm{C}$, ipso-C), 129.0 (2C, o-C), 132.0 (1C, $p$-C), $132.4\left(\mathrm{~d},{ }^{2} J_{\mathrm{C}, \mathrm{P}} 10,2 \mathrm{C}, m-\mathrm{C}\right), 136.8$ (1C, 7-C), 137.1 (1C, 
4-C), 143.4 (d, ${ }^{4} J_{\mathrm{C}, \mathrm{P}} 3,1 \mathrm{C}, p$-C), 146.0 (1C, 10a or 10b-C), 146.1 (1C, 10a or 10b-C), 155.3 (1C, 2 or 9-C), 156.4 (1C, 2 or 9-C), 161.0 (1C, $p$-C). $\delta_{\mathrm{P}}\left(121 \mathrm{MHz}, \mathrm{CDCl}_{3}, 300 \mathrm{~K}\right)$ 18.82. HRMS (ESI): $m / z$ : found: 521.1586; calc. for $\mathrm{C}_{29} \mathrm{H}_{27} \mathrm{~N}_{2} \mathrm{NaO}_{4} \mathrm{P}\left([\mathrm{M}+\mathrm{Na}]^{+}\right)$: 521.1601 .

Tetraethyl ((1,10-phenanthrolin-3,8-diyl)bis(4,1-phenylene)) bis(phosphonate) (10a). A mixture of 3,8-dibromo-1,10phenanthroline (169 mg, $0.5 \mathrm{mmol}$ ), 4-(diethoxyphosphoryl) phenylboronic acid pinacol ester (425 mg, $1.25 \mathrm{mmol}$ ), $\mathrm{Pd}(\mathrm{OAc})_{2}(11.2 \mathrm{mg}, 0.05 \mathrm{mmol}), \mathrm{PPh}_{3}(40 \mathrm{mg}, 0.15 \mathrm{mmol})$ and $\mathrm{Cs}_{2} \mathrm{CO}_{3}(815 \mathrm{mg}, 2.5 \mathrm{mmol})$ in dioxane $(4 \mathrm{~mL})$ was stirred at reflux for $40 \mathrm{~h}$ under Ar. The reaction mixture was cooled to room temperature and filtered. The filtrate was concentrated under reduced pressure and the residue was purified by column chromatography on silica gel (eluent $-\mathrm{CH}_{2} \mathrm{Cl}_{2}$ ). White solid. Yield 52\% (155 mg). $\nu_{\text {max }} / \mathrm{cm}^{-1} 2983(\mathrm{CH}), 1603,1556$, 1475, 1432, 1392, 1365, $1244(\mathrm{P}=\mathrm{O}), 1163,1132,1099,1042$, 1014 (POC), 959 (POC), 937, 838, 815, 793, 762, 731. $\delta_{\mathrm{H}}(300$ $\left.\mathrm{MHz}, \mathrm{CDCl}_{3}, 300 \mathrm{~K}\right) 1.34\left(\mathrm{t},{ }^{3} J_{\mathrm{H}, \mathrm{H}} 7.1,12 \mathrm{H}, \mathrm{Me}\right), 4.15(\mathrm{~m}, 8 \mathrm{H}$, $\left.\mathrm{CH}_{2}\right), 7.86\left(\mathrm{dd},{ }^{3} J_{\mathrm{H}, \mathrm{H}} 8.3,{ }^{4} J_{\mathrm{H}, \mathrm{P}} 3.8,2 \mathrm{H}, o-\mathrm{H}\right), 7.90(\mathrm{~s}, 2 \mathrm{H}, 5,6-\mathrm{H})$, $7.98\left(\mathrm{dd},{ }^{3} J_{\mathrm{H}, \mathrm{P}} 13.0,{ }^{3} J_{\mathrm{H}, \mathrm{H}} 8.3,2 \mathrm{H}, m-\mathrm{H}\right), 8.42\left(\mathrm{~d},{ }^{4} J_{\mathrm{H}, \mathrm{H}} 2.3,2 \mathrm{H}\right.$, 4,7-H), $9.42\left(\mathrm{~d},{ }^{4} J_{\mathrm{H}, \mathrm{H}} 2.3,2 \mathrm{H}, 2,9-\mathrm{H}\right) . \delta_{\mathrm{C}}\left(125 \mathrm{MHz}, \mathrm{CDCl}_{3}, 300\right.$ K) $16.4\left(\mathrm{~d},{ }^{3} J_{\mathrm{C}, \mathrm{P}} 6 \mathrm{~Hz}, 4 \mathrm{C}, \mathrm{Me}\right), 62.3\left(\mathrm{~d},{ }^{2} J_{\mathrm{C}, \mathrm{P}} 5,4 \mathrm{C}, \mathrm{OCH}_{2}\right), 127.35$ (2C, 5,6-C), 127.6 (d, $\left.{ }^{3} J_{\mathrm{C}, \mathrm{P}} 13,4 \mathrm{C}, o-\mathrm{C}\right), 129.2$ (d, ${ }^{1} J_{\mathrm{C}, \mathrm{P}} 187,2 \mathrm{C}$, ipso-C), 129.3 (2C, 4a,6a-C), 132.7 (d, $\left.{ }^{2} J_{\mathrm{C}, \mathrm{P}} 10,4 \mathrm{C}, m-\mathrm{C}\right), 133.9$ (2C, 4,7-C), 134.9 (2C, 3,8-C), 141.4 (d, $\left.{ }^{4} J_{\mathrm{C}, \mathrm{P}} 3,2 \mathrm{C}, p-\mathrm{C}\right), 145.5$ (2C, 10a,10b-C) 149.4 (2C, 2,9-C). $\delta_{\mathrm{P}}\left(121 \mathrm{MHz}, \mathrm{CDCl}_{3}, 300 \mathrm{~K}\right)$ 18.14. HRMS (ESI): $\mathrm{m} / z$ found: 605.1944; calc. for $\mathrm{C}_{32} \mathrm{H}_{34} \mathrm{~N}_{2}$ $\mathrm{NaO}_{6} \mathrm{P}_{2}\left([\mathrm{M}+\mathrm{H}]^{+}\right): 605.1965$.

Tetraethyl ((1,10-phenanthrolin-3,8-diyl)bis([1,10-biphenyl]4,4'-diyl)bis(phosphonate) (11a). A mixture of 3,8-dibromo-1,10phenanthroline (169 mg, $0.5 \mathrm{mmol}), 4$-((diethoxyphosphoryl) phenyl)-4'-phenylboronic acid pinacol ester (520 mg, 1.25 $\mathrm{mmol}$ ), $\mathrm{Pd}(\mathrm{OAc})_{2}$ (11.2 mg, $\left.0.05 \mathrm{mmol}\right), \mathrm{PPh}_{3}$ (40 mg, 0.15 $\mathrm{mmol})$ and $\mathrm{Cs}_{2} \mathrm{CO}_{3}(815 \mathrm{mg}, 2.5 \mathrm{mmol})$ in dioxane $(4 \mathrm{~mL})$ was stirred at reflux for $24 \mathrm{~h}$ under Ar. The reaction mixture was cooled and filtered. The filtrate was concentrated under reduced pressure. The residue was purified by column chromatography on silica gel (eluent $-\mathrm{CH}_{2} \mathrm{Cl}_{2}$ ). White solid. Yield 76\% (226 mg). $\nu_{\max } / \mathrm{cm}^{-1} 2985(\mathrm{CH}), 1601,1493,1476,1434,1388,1367,1236$ $(\mathrm{P}=\mathrm{O}), 1162$, 1132, 1050, 1017 (POC), 939, 917, 848, 822, 780, $733,695 . \delta_{\mathrm{H}}\left(300 \mathrm{MHz}, \mathrm{CDCl}_{3}, 300 \mathrm{~K}\right) 1.34\left(\mathrm{t},{ }^{3} J_{\mathrm{H}, \mathrm{H}} 7.1,12 \mathrm{H}, \mathrm{Me}\right)$, $4.15\left(\mathrm{~m}, 8 \mathrm{H}, \mathrm{CH}_{2}\right), 7.72-7.94(\mathrm{~m}, 18 \mathrm{H}), 8.42\left(\mathrm{~d},{ }^{4} J_{\mathrm{H}, \mathrm{H}} 2.3,2 \mathrm{H}, 4,7-\right.$ $\mathrm{H}), 9.46\left(\mathrm{~d},{ }^{4} J_{\mathrm{H}, \mathrm{H}} 2.3,2 \mathrm{H}, 2,9-\mathrm{H}\right) . \delta_{\mathrm{C}}\left(125 \mathrm{MHz}, \mathrm{CDCl}_{3}, 300 \mathrm{~K}\right) 16.4$ $\left(\mathrm{d},{ }^{3} J_{\mathrm{C}, \mathrm{P}} 6,4 \mathrm{C}, \mathrm{Me}\right), 62.2\left(\mathrm{~d},{ }^{2} J_{\mathrm{C}, \mathrm{P}} 5.3,4 \mathrm{C}, \mathrm{OCH}_{2}\right), 126.9(2 \mathrm{C}, 5,6-\mathrm{C})$, $127.19\left(\mathrm{~d},{ }^{3} J_{\mathrm{C}, \mathrm{P}} 9,4 \mathrm{C}, o-\mathrm{C}\right), 127.75$ (d, ${ }^{1} J_{\mathrm{C}, \mathrm{P}} 187,2 \mathrm{C}$, ipso-C), 128.1 (d, $\left.{ }^{3} J_{\mathrm{C}, \mathrm{P}} 9,8 \mathrm{C}, m, o-\mathrm{C}\right), 129.33$ (2C, 4a,6a-C), 132.5 (d, ${ }^{2} J_{\mathrm{C}, \mathrm{P}} 9,4 \mathrm{C}$, $m$-C), 133.3 (2C, 4,7-C), 135.1 (2C, 3,8-C), 137.3 (2C, Ar-C), 140.0 (2C, Ar-C), 144.2 (d, ${ }^{4} J_{\mathrm{C}, \mathrm{P}} 3,2 \mathrm{C}, p$-C), 145.3 (2C, 10a,10b-C), 149.4 (2C, 2,9-C). $\delta_{\mathrm{P}}\left(121 \mathrm{MHz}, \mathrm{CDCl}_{3}, 300 \mathrm{~K}\right) 18.70$. HRMS (ESI) $\mathrm{m} / \mathrm{z}$ : found: 779.2388; calc. for $\mathrm{C}_{44} \mathrm{H}_{42} \mathrm{~N}_{2} \mathrm{NaO}_{6} \mathrm{P}_{2}\left([\mathrm{M}+\mathrm{H}]^{+}\right)$: 779.2410 .

$\left[\mathbf{C u}(\mathbf{8 a})_{2}\right] \mathbf{P F}_{\mathbf{6}}$ (5a). Phosphonate 8a (125 mg, $\left.0.25 \mathrm{mmol}\right)$ was dissolved in dichloromethane $(5 \mathrm{~mL})$ under Ar. A solution of $\left[\mathrm{Cu}\left(\mathrm{CH}_{3} \mathrm{CN}\right)_{4}\right] \mathrm{PF}_{6}(46.6 \mathrm{mg}, 0.125 \mathrm{mmol})$ in $\mathrm{CH}_{2} \mathrm{Cl}_{2}(10 \mathrm{~mL})$ was prepared under Ar and then added with a syringe to the stirred solution of the ligand. The reaction mixture was stirred at room temperature for $10 \mathrm{~min}$, and then concentrated under reduced pressure. The solid residue was dissolved in $\mathrm{CH}_{2} \mathrm{Cl}_{2}(2 \mathrm{~mL})$ and the solution was layered with diethyl ether $(10 \mathrm{~mL})$. The precipitate was collected by filtration and then dried under vacuum. Brown crystals. Yield 80\% (110 mg). $\nu_{\max } / \mathrm{cm}^{-1} 2982$ (CH), 2906 (CH), 1605, 1552, 1545, 1490, 1422, 1391, 1358, 1322, 1303, $1247(\mathrm{P}=\mathrm{O})$, 1175, 1134, 1110, 1042, 1014 (POC), 959 (POC), 904, 867, 834, 782, 750, 722. $\delta_{\mathrm{H}}\left(500 \mathrm{MHz}, \mathrm{CD}_{2} \mathrm{Cl}_{2}, 300 \mathrm{~K}\right)$ $1.26\left(\mathrm{t},{ }^{3} \mathrm{~J}_{\mathrm{H}, \mathrm{H}} 7.1,12 \mathrm{H}, \mathrm{Me}\right), 3.45(\mathrm{~s}, 6 \mathrm{H}, \mathrm{OMe}), 3.95\left(\mathrm{~m}, 8 \mathrm{H}, \mathrm{CH}_{2}\right)$, $5.99\left(\mathrm{~d},{ }^{3} J_{\mathrm{H}, \mathrm{H}} 8.4,4 \mathrm{H}, m-\mathrm{H}\right), 7.04\left(\mathrm{dd},{ }^{3} J_{\mathrm{H}, \mathrm{P}} 12.6,{ }^{3} J_{\mathrm{H}, \mathrm{H}} 8.0,4 \mathrm{H}, m-\right.$ $\mathrm{H}), 7.31\left(\mathrm{~d},{ }^{3} J_{\mathrm{H}, \mathrm{H}} 8.4,4 \mathrm{H}, o-\mathrm{H}\right), 7.62\left(\mathrm{dd},{ }^{3} J_{\mathrm{H}, \mathrm{H}} 8.0,{ }^{4} J_{\mathrm{H}, \mathrm{P}} 2.4,4 \mathrm{H}, o-\right.$ $\mathrm{H}), 7.85\left(\mathrm{~d},{ }^{3} J_{\mathrm{H}, \mathrm{H}} 8.3,2 \mathrm{H}\right), 7.93\left(\mathrm{~d},{ }^{3} J_{\mathrm{H}, \mathrm{H}} 8.3,2 \mathrm{H}\right), 8.06(\mathrm{~s}, 4 \mathrm{H})$, $8.48\left(\mathrm{~d},{ }^{3} J_{\mathrm{H}, \mathrm{H}} 8.3,2 \mathrm{H}\right), 8.59\left(\mathrm{~d},{ }^{3} J_{\mathrm{H}, \mathrm{H}} 8.3,2 \mathrm{H}\right) . \delta_{\mathrm{P}}(121 \mathrm{MHz}$, $\mathrm{CD}_{2} \mathrm{Cl}_{2}, 300 \mathrm{~K}$ ) 18.81. HRMS (ESI): $\mathrm{m} / z$ found 1059.2703 ; calc. for $\mathrm{C}_{58} \mathrm{H}_{54} \mathrm{CuN}_{4} \mathrm{O}_{8} \mathrm{P}_{2}$ : $\left(\left[\mathrm{M}-\mathrm{PF}_{6}\right]^{+}\right)$1059.2707.

General procedure for the preparation of silyl phosphonate esters 6b-11b. To a $0.1 \mathrm{M}$ solution of diethyl phosphonate esters 6a-11a in dry dichloromethane TMSBr (6 equiv. for each diethoxyphosphoryl group) was added under $\mathrm{Ar}$ and the resulting mixture was stirred at room temperature until a complete conversion of diethyl esters as indicated by ${ }^{1} \mathrm{H}$ NMR spectroscopy (24-48 h). Evaporation of volatiles under reduced pressure afforded silyl phosphonate esters $\mathbf{6 b - 1 1 b}$ in quantitative yield. The compounds were introduced in the next step without additional purification.

Bis(trimethylsilyl) ((1,10-phenanthrolin-3-yl)phosphonate) (6b). $\delta_{\mathrm{H}}\left(300 \mathrm{MHz}, \mathrm{CDCl}_{3}, 300 \mathrm{~K}\right) 0.25$ (s, 18H, Me), 7.65 (dd, $\left.{ }^{3} J_{\mathrm{H}, \mathrm{H}} 8.1,{ }^{3} J_{\mathrm{H}, \mathrm{H}} 4.3,1 \mathrm{H}, 8-\mathrm{H}\right), 7.82\left(\mathrm{~d},{ }^{3} J_{\mathrm{H}, \mathrm{H}} 9.2 \mathrm{~Hz}, 1 \mathrm{H}, 6-\mathrm{H}\right), 7.85$ $\left(\mathrm{d},{ }^{3} J_{\mathrm{H}, \mathrm{H}} 9.2,1 \mathrm{H}, 5-\mathrm{H}\right), 8.26\left(\mathrm{dd},{ }^{3} J_{\mathrm{H}, \mathrm{H}} 8.1,{ }^{4} J_{\mathrm{H}, \mathrm{H}} 1.7,1 \mathrm{H}, 7-\mathrm{H}\right), 8.68$ $\left(\mathrm{dd},{ }^{3} J_{\mathrm{H}, \mathrm{P}} 15.2,{ }^{4} J_{\mathrm{H}, \mathrm{H}} 2.0,1 \mathrm{H}, 4-\mathrm{H}\right), 9.17\left(\mathrm{dd},{ }^{3} J_{\mathrm{H}, \mathrm{H}} 4.3,{ }^{4} J_{\mathrm{H}, \mathrm{H}} 1.7\right.$, $1 \mathrm{H}, 9-\mathrm{H}), 9.33\left(\mathrm{dd},{ }^{3} J_{\mathrm{H}, \mathrm{P}} 5.4,{ }^{4} J_{\mathrm{H}, \mathrm{H}} 2.0,1 \mathrm{H}, 9-\mathrm{H}\right) . \delta_{\mathrm{P}}(121 \mathrm{MHz}$, $\left.\mathrm{CDCl}_{3}, 300 \mathrm{~K}\right)-3.61$.

(1,10-Phenanthrolin-3-yl)phosphonic acid (6c). To a solution of $6 \mathrm{a}(79.1 \mathrm{mg}, 0.25 \mathrm{mmol})$ in dry $\mathrm{CH}_{2} \mathrm{Cl}_{2}(2.5 \mathrm{~mL}) \mathrm{TMSBr}(198$ $\mu \mathrm{L}, 1.5 \mathrm{mmol}$ ) was added under $\mathrm{Ar}$ and the resulting mixture was stirred at room temperature until a complete conversion of the diethyl ester as indicated by ${ }^{1} \mathrm{H}$ NMR spectroscopy (24 h). Then $\mathrm{MeOH}(100 \mu \mathrm{L})$ was added and the reaction mixture was filtered. The precipitate was washed with $\mathrm{MeOH}(1 \mathrm{~mL} \times 2)$, $\mathrm{CH}_{2} \mathrm{Cl}_{2}(1 \mathrm{~mL})$ and dried under reduced pressure. White solid. Yield 98\% (63.7 mg). Found C 55.27, H 3.35, N 10.98. Calc. for $\mathrm{C}_{12} \mathrm{H}_{9} \mathrm{~N}_{2} \mathrm{O}_{3} \mathrm{P}$ : C 55.39; H 3.49; N 10.77\%. $\delta_{\mathrm{H}}\left(300 \mathrm{MHz}, \mathrm{CD}_{3} \mathrm{OD}\right.$, $300 \mathrm{~K})$ 8.35-8.45 (m, 3H, 5,6,8-H), 9.09 (d, $\left.{ }^{3} J_{\mathrm{HP}} 14.5,1 \mathrm{H}, 4-\mathrm{H}\right)$, 9.31-9.37 (br. m, 2H, 7,9-H), 9.50 (d, $\left.{ }^{3} J_{\mathrm{HP}} 5.5,1 \mathrm{H}, 2-\mathrm{H}\right) . \delta_{\mathrm{P}}(300$ $\left.\mathrm{MHz}, \mathrm{CD}_{3} \mathrm{OD}, 300 \mathrm{~K}\right) 12.16$.

\section{Immobilization of copper complexes $\mathrm{Cu} / \mathrm{Pphen}$}

General procedure for the preparation of $\mathrm{Cu} / \mathrm{Pphen} / \mathrm{SG}$ xerogels. Silyl phosphonate ester $\mathbf{6 b}$ or $\mathbf{9 b}$ was dissolved in THF and treated with solid $\mathrm{Cu}\left(\mathrm{PPh}_{3}\right)_{3} \mathrm{Br}$ at room temperature for 30 min to obtain complexes $\mathbf{1 b}$ or $\mathbf{3 b}$, respectively. Then a $0.8 \mathrm{M}$ solution of $\mathrm{Ti}(\mathrm{O} i \mathrm{Pr})_{4}$ in $\mathrm{THF}$ was added to yield a transparent coloured solution. After stirring the resulting mixture for $40 \mathrm{~min}$, water diluted by THF ( $5 \mathrm{M}$ solution) was added dropwise to this solution. A rapid formation of gels or precipitates was observed. The reaction mixture was kept without stirring for $48 \mathrm{~h}$ at room temperature. The precipitate was collected by filtration, washed with THF, methanol and diethyl ether and dried under reduced 
pressure $(2 \mathrm{mmHg})$ at $80{ }^{\circ} \mathrm{C}$ for $24 \mathrm{~h}$. The amounts of reagents and solvents employed for the preparation of complexes $\mathbf{1} \mathbf{b}$ and $\mathbf{3 b}$ and in the sol-gel process, and yields of $\mathbf{C u} / \mathbf{P p e n} / \mathbf{S G}$ xerogels are summarized in Table $\mathrm{S} 1 . \dagger$ Elemental analyses of xerogels $\mathbf{C u}$ / Ppen/SG are reported in Tables S2 and S3. $\dagger$

Complex $\mathrm{Cu}(\mathbf{6 b})\left(\mathrm{PPh}_{3}\right) \mathrm{Br}(\mathbf{1 b})$ is sensitive to moisture and was characterized by ${ }^{1} \mathrm{H}$ and ${ }^{31} \mathrm{P}$ spectroscopy in a crude mixture obtained after evaporation of volatiles. This mixture contains the complex $\mathbf{1 b}$ and $\mathrm{PPh}_{3}$.

$\mathbf{C u}(6 \mathbf{b})\left(\mathbf{P P h}_{3}\right) \mathbf{B r}(\mathbf{1 b}) . \delta_{\mathrm{H}}\left(300 \mathrm{MHz}, \mathrm{CDCl}_{3}, 300 \mathrm{~K}\right) 0.21(\mathrm{~s}$, $18 \mathrm{H}, \mathrm{Me}), 7.19(\mathrm{~m}, 9 \mathrm{H}, m, p-\mathrm{H}), 7.29(\mathrm{~m}, 6 \mathrm{H}, o-\mathrm{H}), 7.82(\mathrm{br} \mathrm{s}, 1 \mathrm{H}$, 8-H), 8.05 (br. d, ${ }^{3} J_{\mathrm{H}, \mathrm{H}} 8.8,1 \mathrm{H}, 6-\mathrm{H}$ ), 8.18 (br. d, ${ }^{3} J_{\mathrm{H}, \mathrm{H}} 8.8,1 \mathrm{H}, 5-$ H), 8.65 (br s, $1 \mathrm{H}, 7-\mathrm{H}), 8.75$ (br s, $1 \mathrm{H}, 4-\mathrm{H}), 8.80$ (br s, $1 \mathrm{H}, 9-\mathrm{H}$ ), 9.15 (br s, $1 \mathrm{H}, 2-\mathrm{H}) . \delta_{\mathrm{P}}\left(121 \mathrm{MHz}, \mathrm{CDCl}_{3}, 300 \mathrm{~K}\right.$ ) -4.67 (br s).

General procedure for the surface modification of mesoporous titanium oxide. Silyl phosphonate esters $\mathbf{6 b}-\mathbf{8 b}$ were dissolved in $\mathrm{CH}_{2} \mathrm{Cl}_{2}$ and treated with solid $\mathrm{Cu}\left(\mathrm{PPh}_{3}\right)_{3} \mathrm{Br}$ or $\left[\mathrm{Cu}\left(\mathrm{CH}_{3} \mathrm{CN}\right)_{4}\right] \mathrm{PF}_{6}$ at room temperature for $30 \mathrm{~min}$ under Ar to prepare complexes $\mathbf{1 b}, \mathbf{2 b}, \mathbf{4 b}$ or $\mathbf{5 b}$. After the reaction was completed, a transparent coloured solution was cannulated into a flask containing $\mathrm{TiO}_{2}$ under Ar. The suspension was stirred for 2 days at room temperature. The solid was collected by filtration, washed with THF, methanol and ether and dried for $24 \mathrm{~h}$ at $80^{\circ} \mathrm{C}$ under reduced pressure $(2 \mathrm{mmHg})$. The amounts of reagents and solvents used for the preparation of complexes and the sol-gel process for grafting are reported in Table S4. $\dagger$ Elemental analyses of solids $\mathbf{C u} / \mathbf{P p h e n} / \mathbf{S M}$ are summarized in Tables S5 and S6. $\dagger$

\section{Immobilization of ligands PPhen-Si}

General procedure for the preparation of Pphen/SG xerogels. Silyl phosphonate ester $\mathbf{6 b}$ or $\mathbf{9 b - 1 1 b}$ was dissolved in THF. A $0.8 \mathrm{M}$ solution of $\mathrm{Ti}(\mathrm{O} i \mathrm{Pr})_{4}$ in $\mathrm{THF}$ was added to this solution and the reaction mixture was stirred for $40 \mathrm{~min}$. Then water diluted by THF ( $5 \mathrm{M}$ solution) was added dropwise to this solution. A rapid formation of gels or precipitates was observed. Then the reaction mixture was kept without stirring for $48 \mathrm{~h}$ at room temperature. The precipitate was collected by filtration, washed with THF, methanol and diethyl ether and dried under reduced pressure $(2 \mathrm{mmHg})$ at $80{ }^{\circ} \mathrm{C}$ for $24 \mathrm{~h}$. The amount of reagents and solvents used for the sol-gel process and yields of xerogels Pphen/SG are reported in Table S7. $\dagger$ Elemental analyses of solids Pphen/SG are presented in Table S8. $\dagger$

Surface modification of mesoporous $\mathrm{TiO}_{2}$ by chelate $6 \mathrm{~b}$. Silyl phosphonate diester $\mathbf{6 b}$ prepared from phosphonate $\mathbf{6 a}$ (316 mg, $1 \mathrm{mmol}$ ) was dissolved in $\mathrm{CH}_{2} \mathrm{Cl}_{2}(20 \mathrm{~mL})$ under Ar. A transparent uncoloured solution was cannulated into a flask containing hydrated titanium oxide $(10 \mathrm{mmol})$ under Ar. The suspension was stirred for $48 \mathrm{~h}$ at room temperature. The solid (959 mg) was collected by filtration, washed with $\mathrm{THF}, \mathrm{MeOH}$ and ether and dried for $24 \mathrm{~h}$ at $80{ }^{\circ} \mathrm{C}$ under reduced pressure $(2$ $\mathrm{mmHg}$ ). The elemental analysis of solid $\mathbf{6 b} / \mathbf{S M}$ is reported in Tables S7 and S8.†

\section{Complex formation with grafted ligand $6 b$}

A solution of $\mathrm{Cu}\left(\mathrm{PPh}_{3}\right)_{3} \mathrm{Br}$ or $\left[\mathrm{Cu}\left(\mathrm{CH}_{3} \mathrm{CN}\right)_{4}\right] \mathrm{PF}_{6}$ in $\mathrm{CH}_{2} \mathrm{Cl}_{2}$ was added to the material $\mathbf{6 b} / \mathbf{S M}$ placed into a Schlenk tube under
Ar. The suspension was stirred for $24 \mathrm{~h}$ at room temperature. The brown solids were collected by centrifugation, washed with $\mathrm{CH}_{2} \mathrm{Cl}_{2}, \mathrm{MeOH}$ and diethyl ether and dried under reduced pressure $\left(2 \mathrm{mmHg}\right.$ ) for $24 \mathrm{~h}$ at $80{ }^{\circ} \mathrm{C}$.

The amounts of reagents and yields of materials $\mathrm{Cu} / \mathbf{6 b} / \mathbf{S M}$ are reported in Table $S 9 . \dagger$ Elemental analyses of $\mathbf{C u} / \mathbf{6 b} / \mathbf{S M}$ are summarized in Tables S10 and S11. $\dagger$

\section{Catalytic reactions}

General procedure for Sonogashira-type coupling. An $8 \mathrm{~mL}$ glass vial was charged with the alkyne $(0.75 \mathrm{mmol})$, aryl iodide (0.5 mmol), $\mathrm{Cs}_{2} \mathrm{CO}_{3}(325.8 \mathrm{mg}, 1 \mathrm{mmol}), \mathbf{C u} / \mathbf{6 b} / \mathbf{S M} / \mathbf{A}$ (43 mg, 5 $\mathrm{mol} \%$, calculated on the grafted complex), $\mathrm{PPh}_{3}$ (13.1 mg, 10 mol\%) and toluene ( $2 \mathrm{~mL}$ ) under Ar. The vial was closed with a Teflon cap and the reaction mixture was stirred at reflux for $16 \mathrm{~h}$. After cooling to room temperature, the organic phase was separated by centrifugation, and the solid catalyst was washed with toluene $(2 \mathrm{~mL})$ and $\mathrm{MeOH}(5 \mathrm{~mL} \times 2)$. The combined toluene phases were evaporated to dryness under reduced pressure. The crude products were analysed by ${ }^{1} \mathrm{H}$ NMR spectroscopy. Mesitylene was used as an internal standard. The spectral data of coupling products were in good agreement with the literature data. ${ }^{70-75}$ The results are summarized in Table 5 (entries 2, 7-16) and Scheme 6.

Recycling of $\mathbf{C u} / \mathbf{6 b} / \mathbf{S M} / \mathrm{A}$ in the reaction of phenylacetylene with $p$-iodoanisole was carried out. After washing with toluene and $\mathrm{MeOH}$, the catalyst was dried under reduced pressure for $3 \mathrm{~h}$ and used in the next reaction cycle as reported above for the freshly prepared $\mathbf{C u} / \mathbf{6 b} / \mathbf{S M} / \mathbf{A}$. The results are summarized in Table 5 (entries 3-6).

A hot filtration test was performed for the reaction of phenylacetylene with $p$-iodoanisole (Table 5, entry 2). After $1 \mathrm{~h}$ of heating, half of the reaction mixture was taken with a syringe equipped with an Acrodisc ${ }^{\circledR}$ syringe filter with a Supor® membrane (pore size $10 \mu \mathrm{m}$ ) and transferred into an $8 \mathrm{~mL}$ glass vial under Ar. The vial was charged with $\mathrm{Cs}_{2} \mathrm{CO}_{3}(163 \mathrm{mg}$, $0.5 \mathrm{mmol}$ ) and $\mathrm{PPh}_{3}(6.6 \mathrm{mg}, 10 \mathrm{~mol} \%)$. Then both reaction mixtures were stirred at reflux for an additional $12 \mathrm{~h}$ and monitored by ${ }^{1} \mathrm{H}$ NMR spectroscopy. The results are shown in Fig. S40.†

The reaction of phenylacetylene with $p$-iodoanisole (Table 5 , entry 2) was also performed using materials $\mathbf{3 b} / \mathbf{S G} / \mathbf{2 0}$ and $\mathbf{3 b} /$ SG/10 as catalysts. The material loading was calculated based on the copper content to obtain $5 \mathrm{~mol} \%$ of grafted complex. In both cases, complete conversion of aryl halide was not achieved even after $72 \mathrm{~h}$ of reflux.

To compare the catalytic activity of materials $\mathbf{1 b} / \mathbf{S M}$ and $\mathbf{2 b}$ / $\mathbf{S M}$, the reaction of phenylacetylene with $p$-iodoanisole (Table 5 , entry 2) was performed in the presence of catalysts containing 5 mol\% of grafted ligands. The conversion of aryl halide was 99 and $60 \%$, respectively, after $72 \mathrm{~h}$ of heating. The catalytic properties of materials $\mathbf{4 b} / \mathbf{S M}$ and $\mathbf{5 b} / \mathbf{S M}$ with respect to this reaction were also investigated using $5 \mathrm{~mol} \%$ of grafted catalysts. For both materials, no coupling products were obtained after $16 \mathrm{~h}$ of reflux.

General procedure for Huisgen cycloaddition. An $8 \mathrm{~mL}$ glass vial was charged with the alkyne $(0.25 \mathrm{mmol})$, azide (0.25 
mmol), triethylamine $(34.7 \mu \mathrm{L}, 0.25 \mathrm{mmol}), \mathbf{C u} / \mathbf{6 b} / \mathbf{S M} / \mathbf{A}$ (4.3 mg, $1 \mathrm{~mol} \%$, calculated on the grafted complex) and fresh distilled THF (1 mL) under Ar. The vial was closed with a Teflon cap and the reaction mixture was stirred at $60{ }^{\circ} \mathrm{C}$ for $3 \mathrm{~h}$. After cooling to room temperature, the organic phase was separated by centrifugation, and the solid catalyst was washed with THF $(1 \mathrm{~mL})$ and methanol $(1 \mathrm{~mL} \times 2)$, and separated by centrifugation. The combined THF phases were evaporated to dryness under reduced pressure. The crude products were analysed by using ${ }^{1} \mathrm{H}$ NMR spectroscopy. Mesitylene was added as an internal standard. The spectral data of the obtained products were in good agreement with the literature data. $^{76-80}$ The product yields are presented in Table 6 .

A hot filtration test was performed for the reaction of phenylacetylene with $p$-nitrobenzyl azide (Table 6, entry 1 ). After $1 \mathrm{~h}$ of heating, half of the reaction mixture was taken with a syringe equipped with an Acrodisc $®$ syringe filter with a Supor ${ }^{\circledR}$ membrane (pore size $10 \mu \mathrm{m}$ ) and introduced into an $8 \mathrm{~mL}$ glass vial under Ar. Then both reaction mixtures were stirred at reflux for an additional $2 \mathrm{~h}$ and monitored by ${ }^{1} \mathrm{H}$ NMR spectroscopy. The results are shown in Fig. S41. $\dagger$

Recycling of $\mathbf{C u} / \mathbf{6 b} / \mathbf{S M} / \mathrm{A}$ in the reaction of phenylacetylene with $p$-nitrobenzyl azide (Table 6, entry 1 ) was carried out. After washing, the catalyst was separated by centrifugation and dried under reduced pressure for $3 \mathrm{~h}$ and used in the next reaction cycle as reported above for the freshly prepared $\mathbf{C u / 6 b / S M / A}$. The product yields in 10 consecutive catalytic reactions are shown in Fig. 6.

\section{Results and discussion}

\section{Preparation of heterogenized catalysts}

Synthesis of copper(I) complexes bearing phosphonate anchoring groups. Recently, we reported the synthesis of air and moisture stable copper(I) complexes with (diethoxyphosphoryl) phenanthroline and triphenylphosphine ligands (1a-3a) which catalyzed $\mathrm{C}-\mathrm{C}$ and $\mathrm{C}-\mathrm{Het}(\mathrm{Het}=\mathrm{N}, \mathrm{P})$ cross-coupling reactions. ${ }^{\mathbf{6 4 , 6 5 , 8 1}}$ These complexes could also be useful for the preparation of heterogeneous catalysts if the diethoxyphosphoryl substituent could be transformed into more reactive phosphonic acid or bis(trimethylsiloxy)phosphoryl groups (Scheme 1). ${ }^{53,82,83}$

Generally, the reaction of dialkyl phosphonic acid esters with TMSBr affords trimethylsilyl (TMS) diesters in high yields under mild conditions. However, when a solution of complex 1a was reacted with TMSBr in $\mathrm{CH}_{2} \mathrm{Cl}_{2}$ at room temperature a complicated mixture of products was obtained according to ${ }^{31} \mathrm{P}$ NMR analysis. Therefore, we decided to introduce the phosphorus anchoring group before the insertion of copper ions into chelators 6-11 (Scheme 2).

First, phosphonic acid $\mathbf{6 c}$ was chosen as a model ligand. This compound was prepared in high yield (98\%) by the treatment of diester $6 \mathbf{a}$ with TMSBr followed by addition of $\mathrm{MeOH}$. The acid $\mathbf{6 c}$ was stable in air but hardly soluble in any organic solvent and aqueous media. All our attempts to prepare copper complexes by reacting this ditopic chelator with tris(triphenylphosphine) copper(I) bromide $\left(\mathrm{Cu}\left(\mathrm{PPh}_{3}\right)_{3} \mathrm{Br}\right)$ or tetrakis(acetonitrile)copper(I) hexafluorophosphate $\left(\left[\mathrm{Cu}\left(\mathrm{CH}_{3} \mathrm{CN}\right)_{4}\right] \mathrm{PF}_{6}\right)$ were unsuccessful, probably due to a low selectivity of the complexation reaction under the studied experimental conditions.

Next, bis(TMS) (1,10-phenanthrolinyl)phosphonic acid esters $\mathbf{6 b - 9 b}$ were prepared by reacting compounds $\mathbf{6 a - 9 a}$ with TMSBr in dichloromethane at room temperature and monitored by ${ }^{1} \mathrm{H}$ NMR spectroscopy. These moisture sensitive compounds were obtained in quantitative yields and introduced in the next step without additional purification. Thus, after the reaction of $\mathbf{6 a}, 7 \mathbf{a}$ and $9 \mathbf{a}$ with $\mathrm{TMSBr}$ proceeded to completion, the volatiles were evaporated to dryness and the residue was reacted with $\mathrm{Cu}\left(\mathrm{PPh}_{3}\right)_{3} \mathrm{Br}$ in $\mathrm{CH}_{2} \mathrm{Cl}_{2}$ to prepare heteroleptic complexes $\mathbf{1 b}-\mathbf{3 b}$. Alternatively, ligands $\mathbf{6 b}$ and $\mathbf{8 b}$
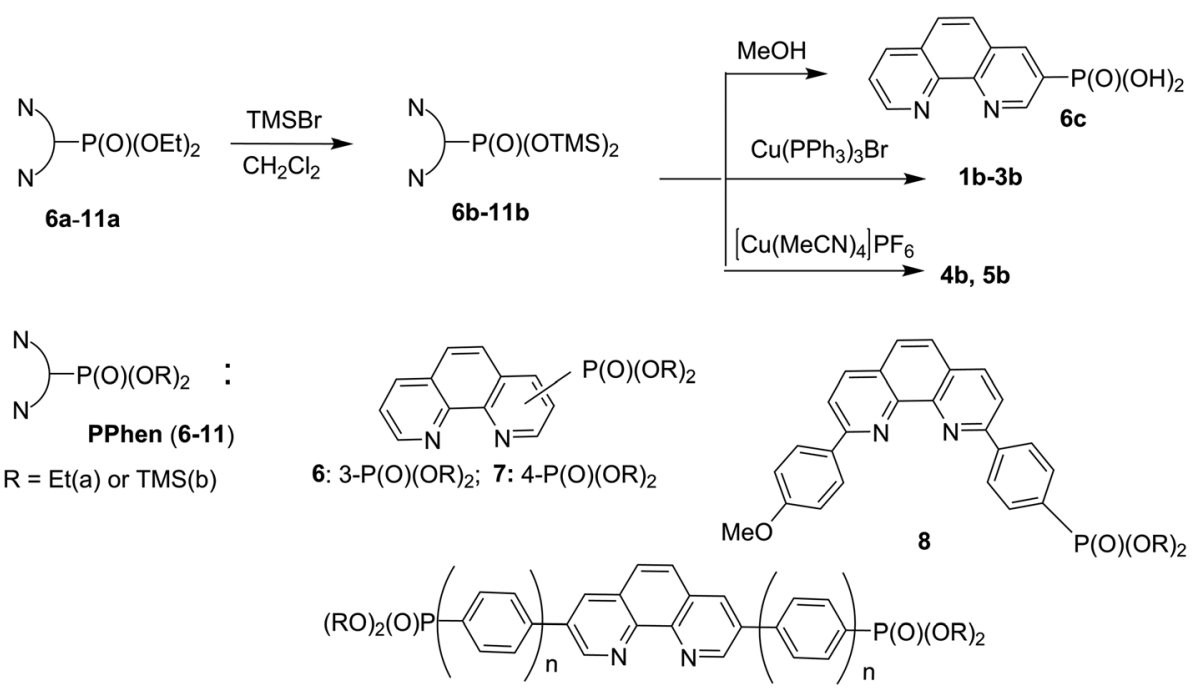

9: $n=0 ; 10: n=1 ; 11: n=2$

Scheme 2 Synthesis of molecular building blocks for the preparation of hybrid materials: silyl esters $6 \mathrm{~b}-11 \mathrm{~b}$, phosphonic acid $6 \mathrm{c}$ and copper complexes $1 b-5 b$. 
were treated with $\left[\mathrm{Cu}\left(\mathrm{CH}_{3} \mathrm{CN}\right)_{4}\right] \mathrm{PF}_{6}$ to yield homoleptic bis(phenanthroline) copper(I) complexes $\mathbf{4 b}$ and $\mathbf{5 b}$, respectively. The progress of complexation was monitored by ${ }^{31} \mathrm{P}$ NMR spectroscopy using the difference in the chemical shift of the phosphorus nuclei of ligands $\mathbf{6 b}-\mathbf{9 b}$ and corresponding complexes 1b-5b ( $\Delta \delta$ 1-2 ppm). After the full consumption of chelators, the volatiles were evaporated and the residues were introduced in the SG process (route A, Scheme 1) or anchored onto the mesoporous titania support prepared by us recently ${ }^{63}$ (route B, Scheme 1).

Preparation of xerogels from copper(I) complexes $1 \mathrm{~b}$ and $\mathbf{3 b}$ (route A, Scheme 1). The first series of materials has been prepared from heteroleptic complexes $\mathbf{1 b}$ and $\mathbf{3 b}$ and $\mathrm{Ti}(\mathrm{O} i \mathrm{Pr})_{4}$ according to the two-step SG process ${ }^{54,84}$ as shown in Scheme 3. This one-pot co-condensation route provides a homogeneous distribution of functional groups within the hybrid solid. Copper complexes $\mathbf{1 b}$ and $\mathbf{3 b}$ were reacted with an excess of $\mathrm{Ti}(\mathrm{O} i \mathrm{Pr})_{4}$ in $\mathrm{THF}$ to form titanium phosphonates (step I). Subsequently, the hydrolysis, condensation and cocondensation reactions (step II) were initiated by a dropwise addition of water diluted by THF to form a polymeric titania network containing covalently linked copper complexes. A gel which was formed immediately was aged at room temperature for two additional days. Then the solid was filtered, washed and dried at $80{ }^{\circ} \mathrm{C}$ under reduced pressure for $24 \mathrm{~h}$.

Five different materials $\mathbf{C u} / \mathbf{1 b} / \mathbf{S G} / \boldsymbol{n}(n=3,10)$ and $\mathbf{C u} / \mathbf{3 b} / \mathbf{S G} /$ $\boldsymbol{n}(n=3,10,20)$ were prepared by varying the $\mathrm{Ti}: \mathrm{Cu}$ molar ratio from 3 to 20 as indicated in Table 1 (see also the ESI, Table S1 $\dagger$ ). The xerogels were first characterized by elemental analysis, inductively coupled plasma optical emission spectroscopy (ICPOES), thermogravimetric (TG) analysis, nitrogen adsorptiondesorption at $77 \mathrm{~K}$ and FTIR spectroscopy. The molar ratios of components used for the material preparation, the chemical composition of xerogels and the calculated Brunauer-EmmettTeller (BET) surface area are summarized in Table 1. Additional data on the material composition and their surface properties are presented in Tables S2, S3 and S12. $\dagger$ The formulae of materials were derived from the contents of six elements $(C, H$, $\mathrm{N}, \mathrm{P}, \mathrm{Ti}, \mathrm{Cu}$ ) assuming the presence of adsorbed water and isopropyl alcohol molecules that is obvious for xerogel samples. As seen in Table 1, the Pphen : $\mathrm{TiO}_{2}$ molar ratio in the materials was close to that of the starting compounds used in the

I. Step I: formation of titanium phosphonates

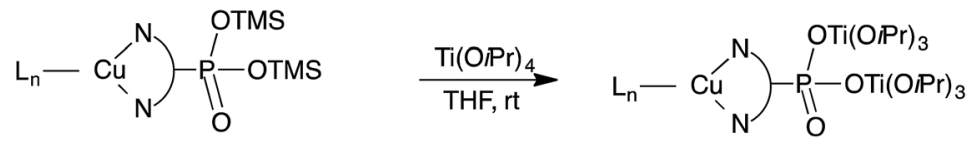

II. Step II: sol-gel processing in organic solvents

Ila. Consecutive hydrolysis
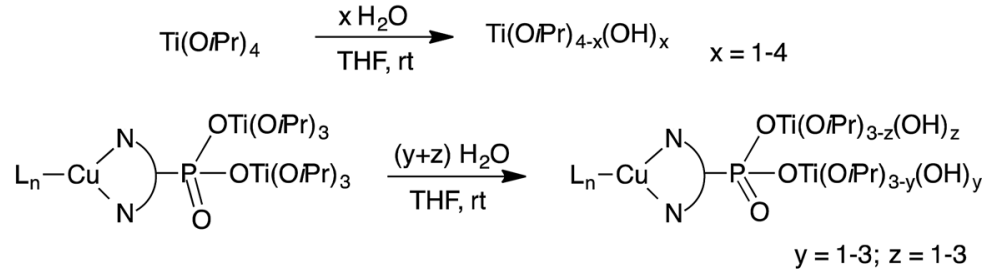

Ilb.Consecutive condensation reactions

Ilc. Consecutive co-condensation reactions

$\mathrm{Ti}(\mathrm{O} / \mathrm{Pr})_{2}(\mathrm{OH})_{2}$

$\downarrow \begin{aligned} & (\mathrm{HO}) \mathrm{Ti}(\mathrm{O} \mathrm{Pr})_{3} \\ & \mathrm{THF}, \mathrm{rt}\end{aligned}$

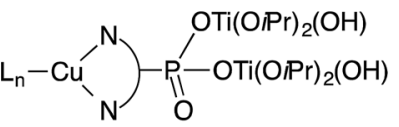

$(\operatorname{PrO})_{2} \mathrm{Ti}(\mathrm{OH})\left(\mathrm{O}-\mathrm{Ti}(\mathrm{O} P r)_{3}\right)+\mathrm{H}_{2} \mathrm{O}$

$\mid \begin{aligned} & (\mathrm{HO}) \mathrm{Ti}(\mathrm{OPPr})_{3} \\ & \mathrm{THF}, \mathrm{rt}\end{aligned}$

$\downarrow \begin{aligned} & (\mathrm{HO}) \mathrm{Ti}(\mathrm{O} I \mathrm{Pr})_{3} \\ & \mathrm{THF}, \mathrm{rt}\end{aligned}$

$(\mathrm{PrO})_{2} \mathrm{Ti}\left(\mathrm{O}-\mathrm{Ti}(\mathrm{OPr})_{3}\right)_{2}+\mathrm{H}_{2} \mathrm{O}$

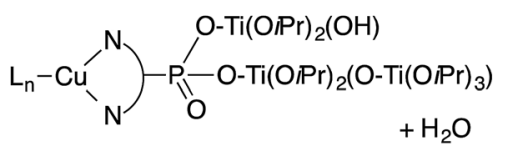

$(\mathrm{HO}) \mathrm{Ti}(\mathrm{O} \mathrm{Pr})_{3}$ $\checkmark \mathrm{THF}, \mathrm{rt}$

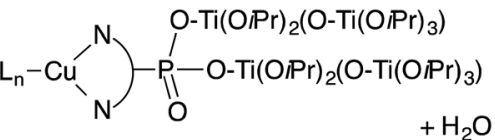

Scheme 3 Representative reactions involved in the preparation of hybrid xerogels Cu/Pphen/SG. 


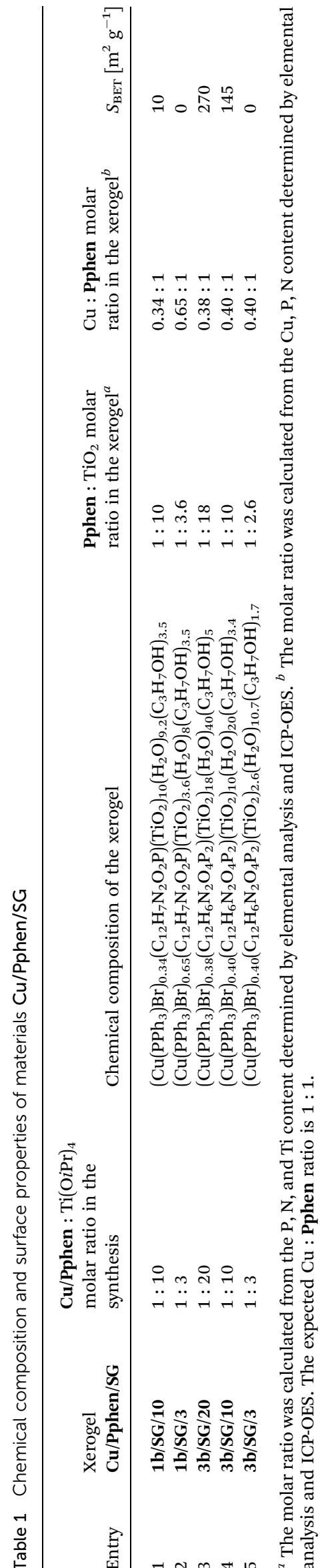

reactions. In contrast, the content of copper atoms in all five $\mathbf{C u}$ / Pphen/SG solids was lower than the expected values. These data indicated that complexes $\mathbf{1 b}$ and $\mathbf{3 b}$ partially dissociated during the SG process. The successful incorporation of PPhen ligands in $\mathbf{C u} / \mathbf{P p h e n} / \mathbf{S G}$ xerogels was further confirmed by the analysis of filtrates obtained after the washing step. Combined liquid phases were evaporated to dryness and analysed by ${ }^{31} \mathrm{P}$ and ${ }^{1} \mathrm{H}$ NMR spectroscopies. The absence of signal sets corresponding to phen derivatives indicated that the incorporation of Pphen into the xerogels was quantitative. Thus, the resulting hybrid materials contain the Pphen and $\mathrm{Cu}(\mathbf{P p h e n})\left(\mathrm{PPh}_{3}\right) \mathrm{Br}$ moieties linked to titania networks.

The presence of adsorbed water and isopropanol molecules in xerogels $\mathbf{1 b} / \mathbf{S G} / \boldsymbol{n}$ and $\mathbf{3 b} / \mathbf{S G} / \boldsymbol{n}$ was confirmed by TG analysis. In general, thermal patterns were similar for all studied samples. As an example, the TG curve of xerogel $\mathbf{3 b} / \mathbf{S G} / \mathbf{2 0}$ is shown in Fig. S22. $\dagger$ A progressive weight loss between 70 and $530{ }^{\circ} \mathrm{C}$ was observed. Accordingly, the separation of the initial loss of adsorbed solvents and the subsequent calcination of organic components was unclear. This thermal behaviour is a typical feature of titania xerogels in which solvent molecules are strongly chemisorbed on the titania surface ${ }^{85-87}$ Nevertheless, semiquantitative consideration of thermal data indicated that the loss of the initial weight for all samples was about 10$15 \%$ when the temperature was increased up to $200-250{ }^{\circ} \mathrm{C}$, which was about a half of maximal percentages of adsorbed solvents calculated from the chemical composition of the solids (Table 1). This difference can be explained by the presence of residual non-hydrolysed isopropoxy groups ( $i \mathrm{PrO}-\mathrm{Ti})$ and noncondensed hydroxy groups (HO-Ti). These moieties are involved in the thermal reactions (condensation and decomposition) only when the temperature rises above $250{ }^{\circ} \mathrm{C}$.

To prove the structure of organic moieties embedded into xerogels $\mathbf{1 b} / \mathbf{S G} / \boldsymbol{n}$ and $\mathbf{3 b} / \mathbf{S G} / \boldsymbol{n}$, and their covalent link to the titania support, FTIR spectra of the solids were recorded (Fig. 2, S23 and S24†). Roughly, the spectra of all hybrid solids were remarkably similar in appearance. In Fig. 2, the FTIR spectrum of $\mathbf{3 b} / \mathbf{S G} / \mathbf{3}$ is compared to those of the relevant ligand $\mathbf{9 a}$ and the heteroleptic copper complex $\mathbf{3 a}$.

Bands having the greatest intensities are located between 900 and $1260 \mathrm{~cm}^{-1}$ and associated with vibrations of the heteroaromatic moiety and its phosphonate substituent. ${ }^{88-90}$ Notably, the shape of the $\mathbf{3 b} / \mathbf{S G} / \mathbf{3}$ spectrum in this region is significantly different from those of ligand $\mathbf{9 a}$ and complex 3a that points to the covalent bonding of the phosphonate group to the titania matrix. In particular, a strong broad band in the 950$1150 \mathrm{~cm}^{-1}$ region observed for the material $\mathbf{3 b} / \mathbf{S G} / \mathbf{3}$ is commonly associated with metal-O-P stretching vibrations..$^{91,92}$ Moreover, characteristic vibrations of the phen heterocycle are also observed in two frequency regions, namely 700-900 and $1350-1600 \mathrm{~cm}^{-1}$ in all three spectra. Despite the overlapping of Pphen and $\mathrm{PPh}_{3}$ vibration bands, the latter can be identified owing to the presence of a relatively strong band at $1430 \mathrm{~cm}^{-1}$ typical of the vibration of the phenyl ring directly attached to a phosphorus atom and a medium band at $690 \mathrm{~cm}^{-1} \cdot{ }^{93} \mathrm{The} \mathrm{O}-\mathrm{H}$ stretching bands at $3500-3700 \mathrm{~cm}^{-1}$, associated with $\mathrm{Ti}-\mathrm{OH}$ groups and adsorbed water, and weak bands in the $2900-3100$ 

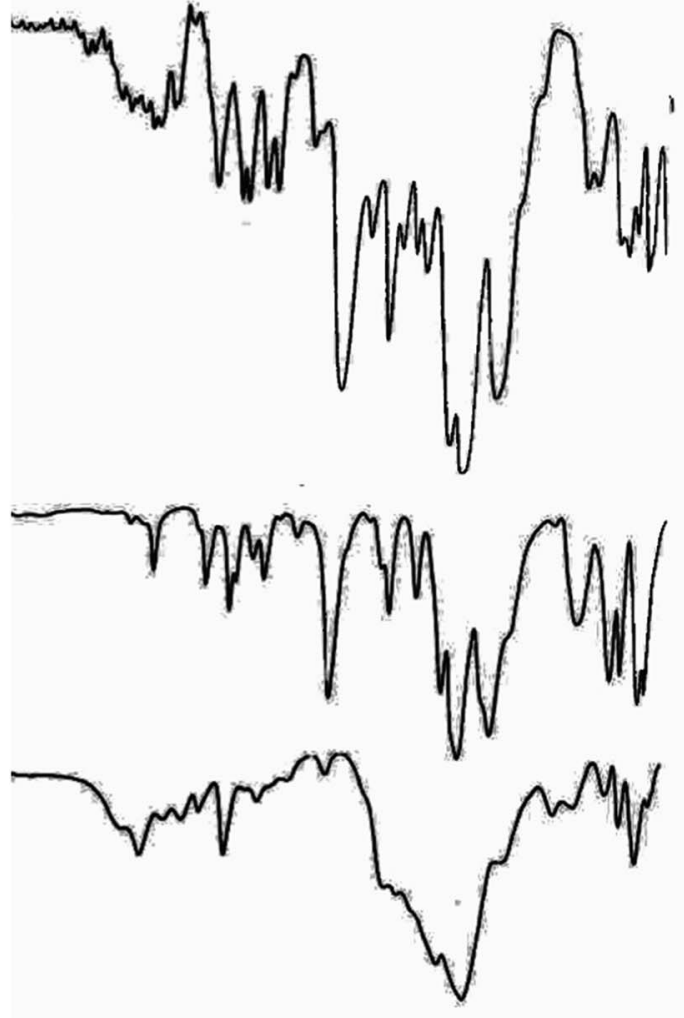

C

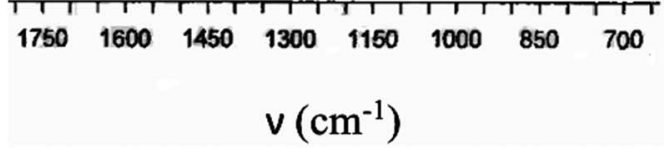

Fig. 2 FTIR spectra of $9 a(A), 3 a(B)$ and $3 b / S G / 3$ (C).

$\mathrm{cm}^{-1}$ region, characteristic of the aromatic and aliphatic $\mathrm{C}-\mathrm{H}$ bonds, are also present in the spectrum of $\mathbf{3 b} / \mathbf{S G} / \mathbf{3}$.

It has to be noted that stretching vibrations of the phosphonate group in the $950-1250 \mathrm{~cm}^{-1}$ region were commonly used for disclosing the binding mode of phosphonate molecules to a titania network. ${ }^{83,91,92}$ However, recently Blockhuys et al. have demonstrated that FTIR spectroscopy is not well suited for the investigation of the bonding mode in hybrid materials because $\mathrm{P}-\mathrm{O}$ and $\mathrm{P}=\mathrm{O}$ stretches also depend on hydrogen bonding. ${ }^{94}$ For solids $\mathbf{1 b} / \mathbf{S G} / \boldsymbol{n}$ and $\mathbf{3 b} / \mathbf{S G} / \boldsymbol{n}$, this analysis is even more complicated due to the overlapping of these stretches with vibrations of the heterocyclic moiety. For example, a weak band at approximately $1250 \mathrm{~cm}^{-1}$ can be assigned to the vibration of the uncoordinated $\mathrm{P}=\mathrm{O}$ group or the heteroaromatic fragment.

Powder X-ray diffraction measurements indicate that all materials are non-crystalline.

The porosity of xerogels $\mathbf{1 b} / \mathbf{S G} / \boldsymbol{n}$ and $\mathbf{3 b} / \mathbf{S G} / \boldsymbol{n}$ was examined by nitrogen adsorption-desorption at $77 \mathrm{~K}$. Interestingly, BET surface areas were dependent on the number of phosphonate groups in phen ligands and the amount of $\mathrm{Ti}(\mathrm{O} i \mathrm{Pr})_{4}$ employed for the incorporation of complexes. Solids $\mathbf{1 b} / \mathbf{S G} / \mathbf{3}$ and $\mathbf{1 b} / \mathbf{S G} /$ 10 containing monophosphonate residues were non-porous.
The material $\mathbf{3 b} / \mathbf{S G} / \mathbf{2 0}$ prepared from the copper complex with (phen)diphosphonate $3 \mathbf{b}$ and 20 equiv. of $\mathrm{Ti}(\mathrm{O} i \mathrm{Pr})_{4}$ exhibited micro- and mesoporosity and a remarkable specific surface area (BET surface area of $270 \mathrm{~m}^{2} \mathrm{~g}^{-1}$ ). However, in a series of xerogels $3 \mathbf{b} / \mathbf{S G} / \mathbf{2 0}-\mathbf{3} \mathbf{b} / \mathbf{S G} / \mathbf{3}$, this value dropped drastically (Tables 1 and S12 $\dagger$ ) with the decrease of titania percentage, which is a serious drawback for their applications in catalysis.

To increase the porosity of hybrid materials and the content of copper ions, another strategy of immobilization was investigated. The complexes were grafted onto a surface of preformed $\mathrm{TiO}_{2}$.

Surface modification of $\mathrm{TiO}_{2}$ by copper(I) complexes (route B, Scheme 1). Recently we have reported the preparation of nonordered mesoporous titania, which exhibited a remarkable specific surface area of $580-650 \mathrm{~m}^{2} \mathrm{~g}^{-1}$ and pore volumes of $0.5-$ $1.2 \mathrm{~cm}^{3} \mathrm{~g}^{-1} \cdot{ }^{63}$ This cost-effective hydrated $\mathrm{TiO}_{2}$ is readily available by a template-free SG process and promising for the preparation of heterogeneous catalysts. A surface modification of $\mathrm{TiO}_{2}$ by phosphonates is shown in Scheme 4. Silyl phosphonate diesters are reacted with a preformed titania support bearing reactive hydroxy groups. Accordingly, water is no more needed for the immobilization and the SM reaction can be performed in all organic solvents in which the targeted complexes can be dissolved. Copper complexes $\mathbf{1 b}$ and $\mathbf{2} \mathbf{b}$ are readily soluble in chlorinated solvents and we chose the weakly coordinating $\mathrm{CH}_{2} \mathrm{Cl}_{2}$ as a reaction medium to prevent the dissociation of copper complexes.

Complexes $\mathbf{1 b}$ and $\mathbf{2 b}$ smoothly reacted with $\mathrm{TiO}_{2}$ powders in $\mathrm{CH}_{2} \mathrm{Cl}_{2}$ at room temperature. Hybrid solids $\mathbf{C u} / \mathbf{P p h e n} / \mathbf{S M}$ were filtered after $48 \mathrm{~h}$ of stirring, dried at $80{ }^{\circ} \mathrm{C}$ under reduced pressure and examined by elemental and ICP-OES analyses (Tables 2 and S4-S6†).

The $\mathrm{Ti}: \mathrm{N}$ and $\mathrm{Ti}: \mathrm{P}$ molar ratios indicated quantitative grafting of Pphen ligands. Surprisingly, $\mathrm{Cu}$ : Pphen molar ratio was low in both materials as it was previously observed for $\mathbf{C u} /$ Ppen/SG xerogels. Thus, once again the resulting hybrid materials contain Pphen and $\mathrm{Cu}(\mathbf{P p h e n})\left(\mathrm{PPh}_{3}\right) \mathrm{Br}$ moieties linked to the titania support. These results can be explained by the kinetic lability of heteroleptic copper complexes (Scheme 5). In fact, according to ${ }^{1} \mathrm{H}$ and ${ }^{31} \mathrm{P}$ NMR studies of chelates $\mathbf{1}$ and 2 only one major species exists in $\mathrm{CDCl}_{3}$ solution for each of these complexes (Fig. S1-S4, S16 and S17†). In these mononuclear species, phen moieties are coordinated to copper centres by two nitrogen atoms and a rapid exchange of Pphen ligands is highly probable. ${ }^{65}$ For example, line broadening in the room temperature ${ }^{1} \mathrm{H}$ NMR spectrum of complex $\mathbf{1 b}$ could be caused by the ligand exchange (Fig. S16 $\dagger$ ). The immobilization of the Pphen ligand which could be present in solution in a low concentration should proceed more rapidly than the incorporation of the bulky heteroleptic complex $\mathbf{C u / P p h e n . ~ A c c o r d i n g l y , ~ t h e ~}$ complexation equilibrium could be moved to the noncoordinated ligand that should provide for the formation of a material modified by free chelator moieties.

To check this hypothesis, kinetically more stable ${ }^{65}$ homoleptic complexes $\mathbf{4 b}$ and $\mathbf{5 b}$ were grafted onto the $\mathrm{TiO}_{2}$ surface (Table 2). As evidenced by $\mathrm{Cu}: \mathrm{Ti}, \mathrm{Cu}: \mathrm{P}$, and $\mathrm{Cu}: \mathrm{N}$ molar 

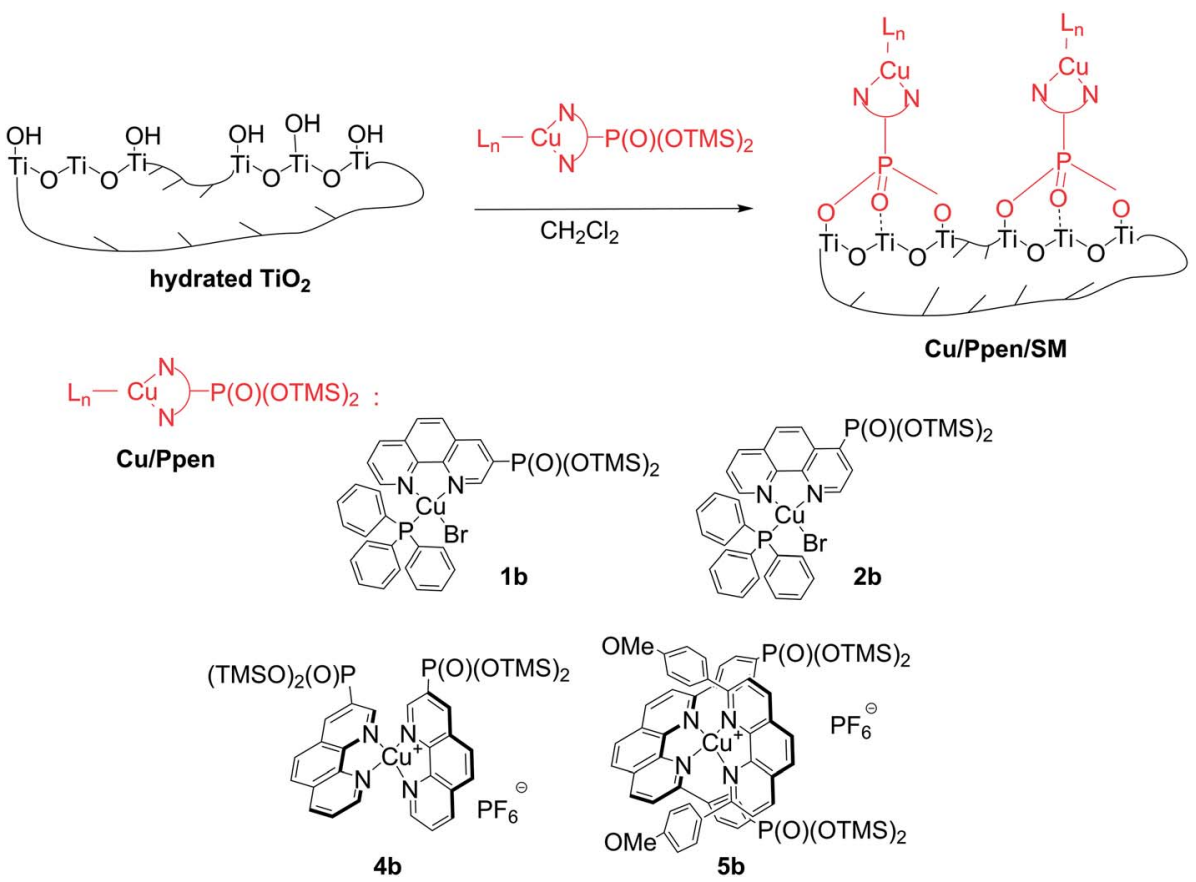

Scheme 4 Schematic representation of grafting of copper(I) complexes with Pphen-Si ligands onto a titania support.

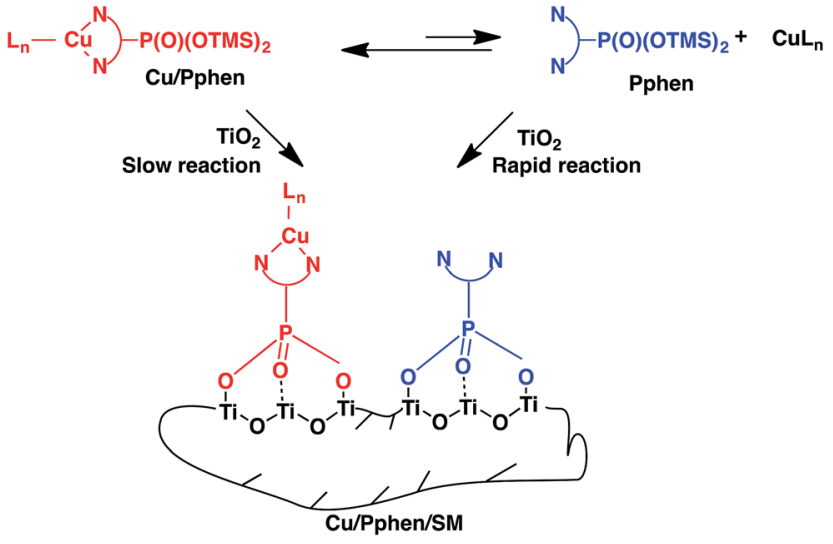

Scheme 5 Schematic representation of the grafting of $\mathrm{Cu} /$ Pphen complexes on the titania support.

ratios obtained for these materials (Table S6†), the immobilization was successful in both cases. FTIR spectra of solids $\mathbf{4 b}$ / SM and 5b/SM shown in Fig. S25 and S26 $\dagger$ corroborated the proposed molecular structures of the materials.

The porosity of $\mathbf{C u} / \mathbf{P p h e n} / \mathbf{S M}$ materials was studied by $\mathrm{N}_{2}$ sorption measurements (Tables 2 and S12 $\dagger$ ). The shapes of all isotherms were similar and resembled that of the non-modified titania support. In contrast, BET surface areas of hybrid materials were smaller compared to that of the as-synthesized $\mathrm{TiO}_{2}$. This indicates the successful grafting of complexes onto a surface of mesopores.

Being unable to overcome the dissociation of heteroleptic copper complexes, we have turned to a stepwise strategy for the preparation of heterogeneous catalysts. This method involves the incorporation of free Pphen ligands into a titania support followed by their complexation with copper ions.

Immobilization of Pphen-Si ligands followed by the insertion of copper ions (routes $C$ and $D$, Scheme 1). The first series of materials have been prepared according to the SG process as described above for copper complexes, with the only difference that Pphen-Si chelators were used as molecular precursors (Schemes 1 and 3). Materials $\mathbf{6 b} / \mathbf{S G}$ and $\mathbf{9 b} / \mathbf{S G}$ were characterized by elemental analysis, ICP-OES, and nitrogen adsorptiondesorption at $77 \mathrm{~K}$ (Tables 3, S7 and S8, $\uparrow$ entries 1 and 2). As seen from these data, $\mathrm{Ti}: \mathrm{N}$ and $\mathrm{Ti}: \mathrm{P}$ molar ratios are very close to theoretical values. However, both solids display a pretty low BET surface area of 215 and $160 \mathrm{~m}^{2} \mathrm{~g}^{-1}$, respectively. Our attempt to increase the xerogel porosity by using bulkier ligands in which the phen moiety and phosphonate substituents were separated by phenyl spacers (compounds $10 \mathrm{~b}$ and 11b, Fig. 1) achieved only a partial success (Table 3 , entries 3 and 4 ). The BET surface areas of xerogels 10b/SG and 11b/SG were 270 and $300 \mathrm{~m}^{2} \mathrm{~g}^{-1}$, respectively, even when $\mathrm{Ti}(\mathrm{O} i \mathrm{Pr})_{4}$ was used in a large excess (20 equiv.).

Next, silyl phosphonate $\mathbf{1 b}$ was grafted onto the surface of $\mathrm{TiO}_{2}$ in $\mathrm{CH}_{2} \mathrm{Cl}_{2}$ at room temperature as described above for copper complexes. As expected, the reaction proceeds quantitatively yielding a porous hybrid material $\mathbf{6 b} / \mathbf{S M}$ which was first characterized by elemental analysis (Tables S7 and S8 $\dagger$ ), EDX spectrometry, FTIR (Fig. S31 $\dagger$ ) and ${ }^{31} \mathrm{P}$ MAS NMR spectroscopies. In particular, the ${ }^{31} \mathrm{P}$ MAS NMR spectrum shows a broad signal typical of non-ordered solids based on titania at about 5 ppm (Fig. 3). The ${ }^{31} \mathrm{P}$ chemical shifts in amorphous titania phosphates were reported between -21 and -4 ppm. ${ }^{95}$ Thus, cleavage of the C-P bond was not observed under these experimental conditions and phosphorus atoms in the material are 


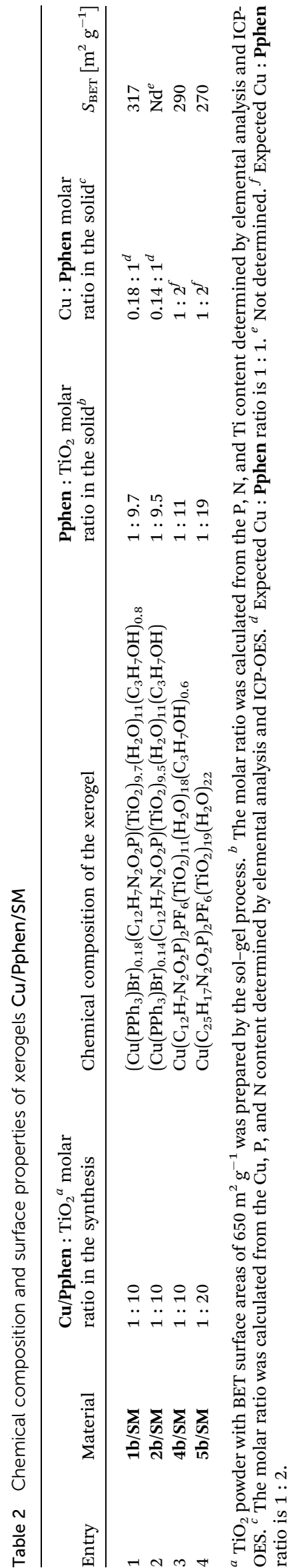

bonded to the phen scaffold and the three oxygen atoms. Phosphorus signals of layered titanium phosphonates are obviously observed at $-4 \mathrm{ppm}$ as sharp signals ${ }^{95}$ that do not match with our spectrum. These data indicate that phen moieties are separated from one another on the titania surface. The experimental spectrum of $\mathbf{6 b} / \mathbf{S M}$ was deconvoluted as shown in Fig. 3. According to this analysis, the experimentally observed signal is a superposition of three sharp resonances originating from non-equivalent phosphorus sites. Based on the relative positions of the three signals in ${ }^{31} \mathrm{P}$ MAS NMR spectra of titania-supported phenylphosphonic acid, ${ }^{\mathbf{8 3}, 94,96}$ the major signal ( $\delta 4.8 \mathrm{ppm}, 80 \%$ ) was attributed to the phosphonate group that exhibited a tridentate binding mode and the other two signals were assigned to mono- $(\delta-2.7 \mathrm{ppm})$ and bidentate ( $\delta 7.2 \mathrm{ppm}$ ) phosphonate groups.

Interestingly, qualitative EDX-STEM analysis of this material indicated the presence of $\mathrm{Br}$ along with the other expected elements (Fig. S34 and S35 $\dagger$ ). We have assumed that the phen ligand was partially protonated by traces of hydrobromic acid when it was reacted with TMSBr.

Nitrogen adsorption-desorption isotherms of solid $6 \mathbf{b} / \mathbf{S M}$ and the bare $\mathrm{TiO}_{2}$ support are presented in Fig. 4A and pore size distributions for these materials are shown in Fig. 4B. The features of the two isotherms are very similar. They demonstrate a gradual increase in the adsorbed nitrogen volume as a function of the relative pressure making a hysteresis loop. The morphology of the curves can be considered as a combination of type II and type IV isotherms that are typical of non-ordered porous solids containing both mesopores and macropores with a large distribution of the pore size. The BET surface area was lowered from 650 to $366 \mathrm{~m}^{2} \mathrm{~g}^{-1}$ after grafting the ligand $\mathbf{6 b}$. This surface modification has also caused a significant decrease in the amount of small mesopores in $\mathrm{TiO}_{2}$ (Fig. 4B).

As can be seen from Tables 3 and S12, $\dagger$ the porosity of the material $\mathbf{6 b} / \mathbf{S M}$ was superior to those of hybrid materials Pphen/SG prepared by the SG method. In addition, in this material, chelator moieties are located on the titania surface and more accessible for reactant molecules than in Pphen/SG materials in which the ligands are buried inside the solids. Thus, 6b/SM material was chosen for the preparation of the heterogeneous catalyst. The insertion of copper ions was performed by stirring this solid with various copper(I) complexes in $\mathrm{CH}_{2} \mathrm{Cl}_{2}$ at room temperature (Table 4). The chelation was sluggish due to the strong steric hindrance induced by the solid support and/or the partial protonation of the titania-supported phen ligand. First, solid $\mathbf{6 b} / \mathbf{S M}$ was reacted with 1.1 equiv. of $\mathrm{Cu}\left(\mathrm{PPh}_{3}\right)_{3} \mathrm{Br}$ which we previously used to prepare related Pphen complexes 1-3 under homogeneous conditions. According to the elemental analysis and ICP-OES data for the resulting materials, $\mathrm{Cu}$ : Pphen molar ratio was only 0.16 (entry 1 ). When $\mathrm{Cu}\left(\mathrm{PPh}_{3}\right)_{3} \mathrm{Br}$ amount was increased up to 2.6 equiv., complexation of $29 \%$ of the grafted ligand was achieved (entry 2). Fortunately, $\left[\mathrm{Cu}(\mathrm{MeCN})_{4}\right] \mathrm{PF}_{6}$ complex bearing less bulky ligands was more reactive and gave the target material $\mathbf{C u} / \mathbf{6 b}$ / SM/A (entry 3). The empirical formula of this material was derived from its elemental analysis (Tables S10 and S11†). In addition, the presence of fluorine in the powder was confirmed 
Table 3 Chemical composition and surface properties of xerogels Pphen/SG

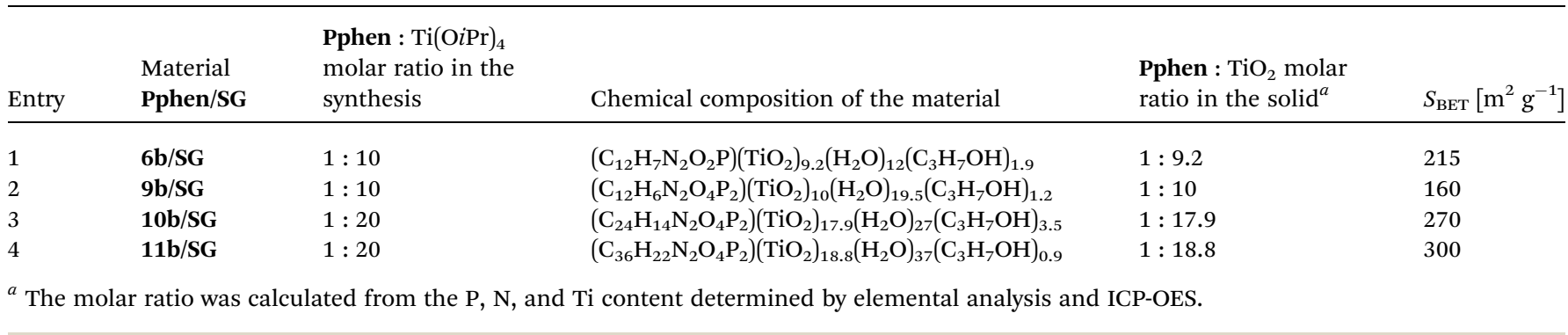

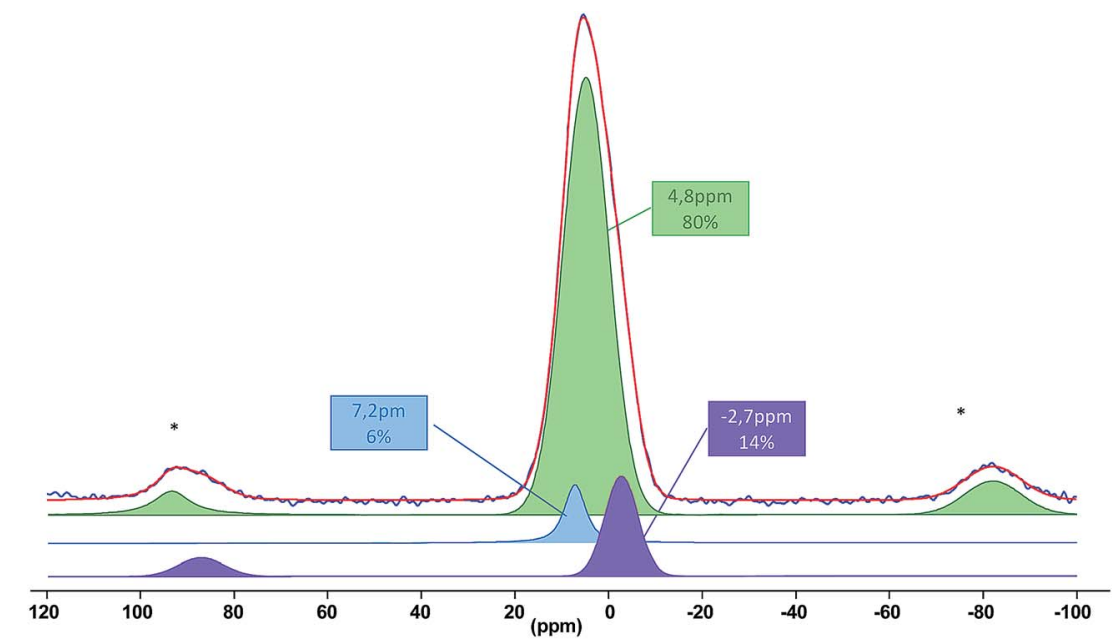

Fig. 3 Experimental (blue) and simulated (red) ${ }^{31} \mathrm{P}$ MAS NMR spectrum of the material 6b/SM. The stars indicate spinning sidebands.

by EDX-TEM analysis (Fig. S36†). It has to be also noted that bromine was not found in the studied sample. These data are in agreement with our hypothesis that the titania-supported phen ligand is partially protonated in the material 6b/SM. Accordingly, the bromide anion is no more present in the solid after the complexation reaction.

The nitrogen adsorption-desorption isotherm of $\mathbf{C u} / \mathbf{6 b} / \mathbf{S M} /$ A at $77 \mathrm{~K}$ is presented in Fig. 4A and compared with those of the bare titania support and starting material 6b/SM. Upon the stepwise derivatization of $\mathrm{TiO}_{2}$, no change in the shape of isotherms was observed, whereas a marked decrease in the BET surface area (from 650 to $243 \mathrm{~m}^{2} \mathrm{~g}^{-1}$, Table $\mathrm{S} 12 \dagger$ ) and pore volume (from 1.36 to $0.55 \mathrm{~cm}^{3} \mathrm{~g}^{-1}$, Table $\mathrm{S} 12 \dagger$ ) was noted, which is consistent with the presence of a significant amount of grafted complex on the surface.

The morphology of solids $\mathbf{6 b} / \mathbf{S M}$ and $\mathbf{C u} / \mathbf{6 b} / \mathbf{S M} / \mathrm{A}$ was studied by SEM and TEM microphotographies and compared with that of the bare $\mathrm{TiO}_{2}$ support. SEM images are shown in
A

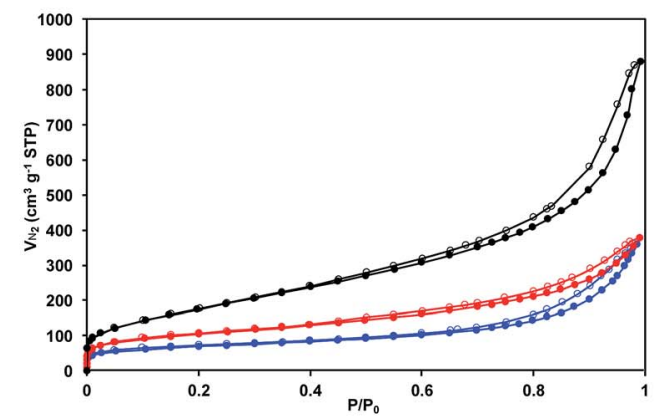

B

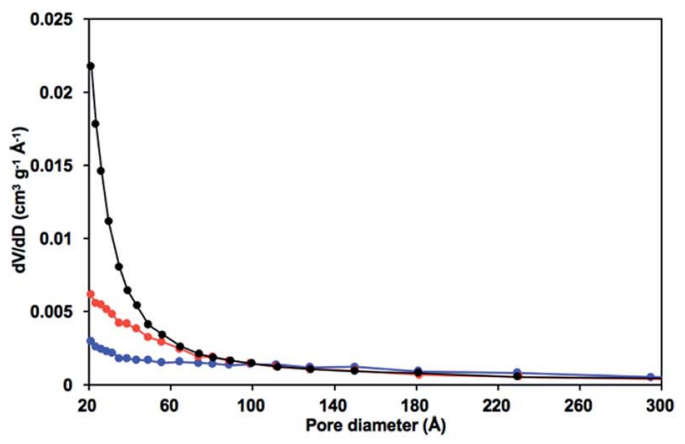

Fig. 4 Nitrogen adsorption-desorption studies: isotherms for as-synthesized hydrated $\mathrm{TiO}_{2}$ (black), solid 6b/SM (red) and Cu/6b/SM/A (blue) (A); pore size distribution (BJH calculations) for as-synthesized $\mathrm{TiO}_{2}$ (black), 6b/SM (red) and Cu/6b/SM/A (blue) (B). 
Table 4 Insertion of copper(I) ions into the material 6b/SM

\begin{tabular}{lllll}
\hline Entry & Solid & $\begin{array}{l}\text { Copper complex } \\
\text { (equiv. of grafted } \mathbf{6 b})\end{array}$ & $\begin{array}{l}\mathrm{Cu}: \mathbf{6 b} \\
\text { molar ratio }\end{array}$ & $\begin{array}{l}S_{\mathrm{BET}} \\
{\left[\mathrm{m}^{2} \mathrm{~g}^{-1}\right]}\end{array}$ \\
\hline 1 & $\mathbf{C u} / \mathbf{6 b} / \mathbf{S M} / \mathbf{P 1}$ & $\mathrm{Cu}\left(\mathrm{PPh}_{3}\right)_{3} \mathrm{Br}(1.1)$ & $0.16: 1$ & $\mathrm{nd}^{b}$ \\
2 & $\mathbf{C u} / \mathbf{6 b} / \mathbf{S M} / \mathbf{P 2}$ & $\mathrm{Cu}\left(\mathrm{PPh}_{3}\right)_{3} \mathrm{Br}(2.6)$ & $0.29: 1$ & $\mathrm{nd}^{b}$ \\
3 & $\mathbf{C u} / \mathbf{6 b} / \mathbf{S M} / \mathbf{A}$ & $\mathrm{Cu}\left(\mathrm{MeCN}_{4} \mathrm{PF}_{6}(2.6)\right.$ & $1: 1$ & 243
\end{tabular}

${ }^{a}$ The molar ratio was calculated from the $\mathrm{Cu}, \mathrm{P}$, and $\mathrm{N}$ content determined by elemental analysis and ICP-OES. ${ }^{b}$ Not determined.

Fig. 5. As-synthesized hydrated $\mathrm{TiO}_{2}$ is composed of strongly aggregated nanoparticles displaying a similar shape and quite narrow distribution of the grain size. As seen in Fig. 5, grafting of the Pphen ligand (material 6b/SM) and the subsequent insertion of copper(I) ions (material $\mathbf{C u} / \mathbf{6 b} / \mathbf{S M} / \mathbf{A}$ ) do not have any influence on the morphology of solids. TEM images of $\mathbf{6 b}$ / $\mathbf{S M}$ and $\mathbf{C u} / \mathbf{6 b} / \mathbf{S M} / \mathbf{A}$ are shown in Fig. S33. $\dagger$ The mesoporous nanospheroids with a diameter ranging from 5 to $20 \mathrm{~nm}$ are irregularly distributed in the space and separated by large widths of hundreds of nanometers. The calculated external specific surface area of non-aggregated anatase nanoparticles of this size is in the range of $75-300 \mathrm{~m}^{2} \mathrm{~g}^{-1}$ that evidences the presence of interior mesopores in at least bare $\mathrm{TiO}_{2}\left(S_{\mathrm{BET}}=650\right.$ $\left.\mathrm{m}^{2} \mathrm{~g}^{-1}\right)$. This morphology perfectly fits the catalytic application providing the accessibility of catalytic sites and mass transfer of reagents and products through large channels separating the nanoparticles. Powder X-ray measurements demonstrate that these samples are non-crystalline (Fig. S37 $\dagger$ ).

All Cu/Pphen/SG and Cu/Pphen/SM materials except 5b/SM change their brown colour to green-blue after exposure to air for a few weeks. Oxidation of copper(I) ions was assumed and proved by EPR spectroscopy and diffuse reflectance spectroscopy. As a representative example, the EPR spectrum of $\mathbf{C u} / \mathbf{6 b}$ / SM/A stored in air is presented in Fig. S38. $\dagger$ The spectrum recorded in X-band frequencies at $100 \mathrm{~K}$ shows a broad line in the region of 2500-3600 $\mathrm{G}$ due to an intermolecular spin exchange caused by spin coupling between paramagnetic copper(II) centres located in close proximity. As a result, the anisotropic $g_{i}$ values cannot be determined by simulation experiments due to the broad linewidth that precluded any studies of a copper ion environment in the solid state. We also observed a very large and weak band in the region of 700$950 \mathrm{~nm}$ in the diffuse reflectance spectrum of $\mathbf{C u} / \mathbf{6 b} / \mathbf{S M} / \mathbf{A}$ due to $\mathrm{d}-\mathrm{d}$ electron transitions in copper(II) complexes. ${ }^{\mathbf{9 7}, \mathbf{9 8}}$ However, the weak intensity of this band and its broadness also excluded any conclusions on the copper(II) ion environment (Fig. S39†).

\section{Catalytic reactions}

Sonogashira coupling. The catalytic cross-coupling reaction of aryl halides with terminal acetylenes is a well-known and useful method in organic synthesis which is frequently employed for the synthesis of biologically active molecules, heterocycles, natural products, or polymers. ${ }^{99,100}$ Commonly, this reaction is performed in anhydrous solvents in the presence of tertiary amines, palladium catalysts and with copper salts as co-catalysts. Palladium-free conditions were also widely explored ${ }^{\mathbf{9 9 1 0 1 - 1 0 3}}$ but heterogenized copper complexes are still limited by a few examples. ${ }^{\mathbf{4 7}, \mathbf{1 0 4 - 1 0 7}}$

In the preliminary experiment, a model reaction of $p$ iodoanisole with phenylacetylene in toluene at $110{ }^{\circ} \mathrm{C}$ was
$\mathbf{A}$

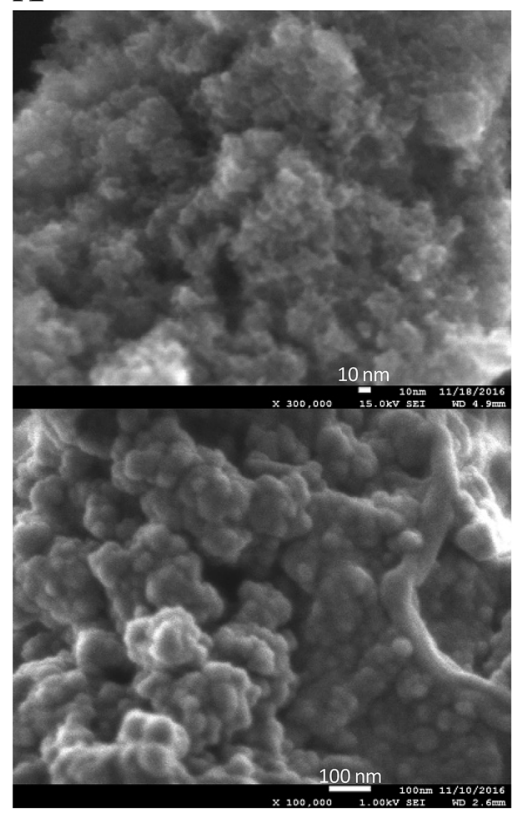

B

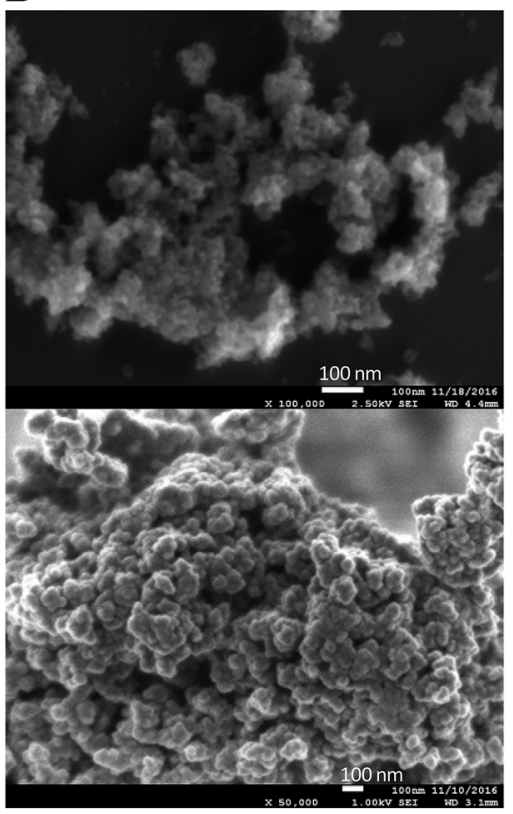

C

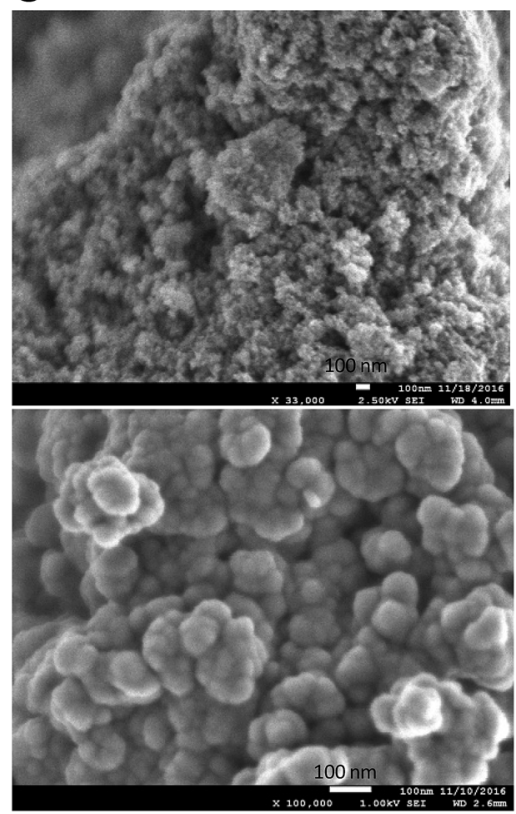

Fig. $5 \mathrm{SEM}$ microphotographs of bare hydrated $\mathrm{TiO}_{2}(\mathrm{~A})$, solid 6b/SM (B) and the material Cu/6b/SM/A (C). Upper microphotographs of each series were obtained from powders deposited on a silicon wafer as ethanol suspensions. Bottom images were observed using samples prepared by the dispersion of the materials on a conductive carbon tape and carbon coating $(8 \mathrm{~nm})$. 
Table 5 Reaction of alkynes with aryl iodides catalysed by $\mathrm{Cu} / 6 \mathrm{~b} / \mathrm{SM} / \mathrm{A}^{a}$

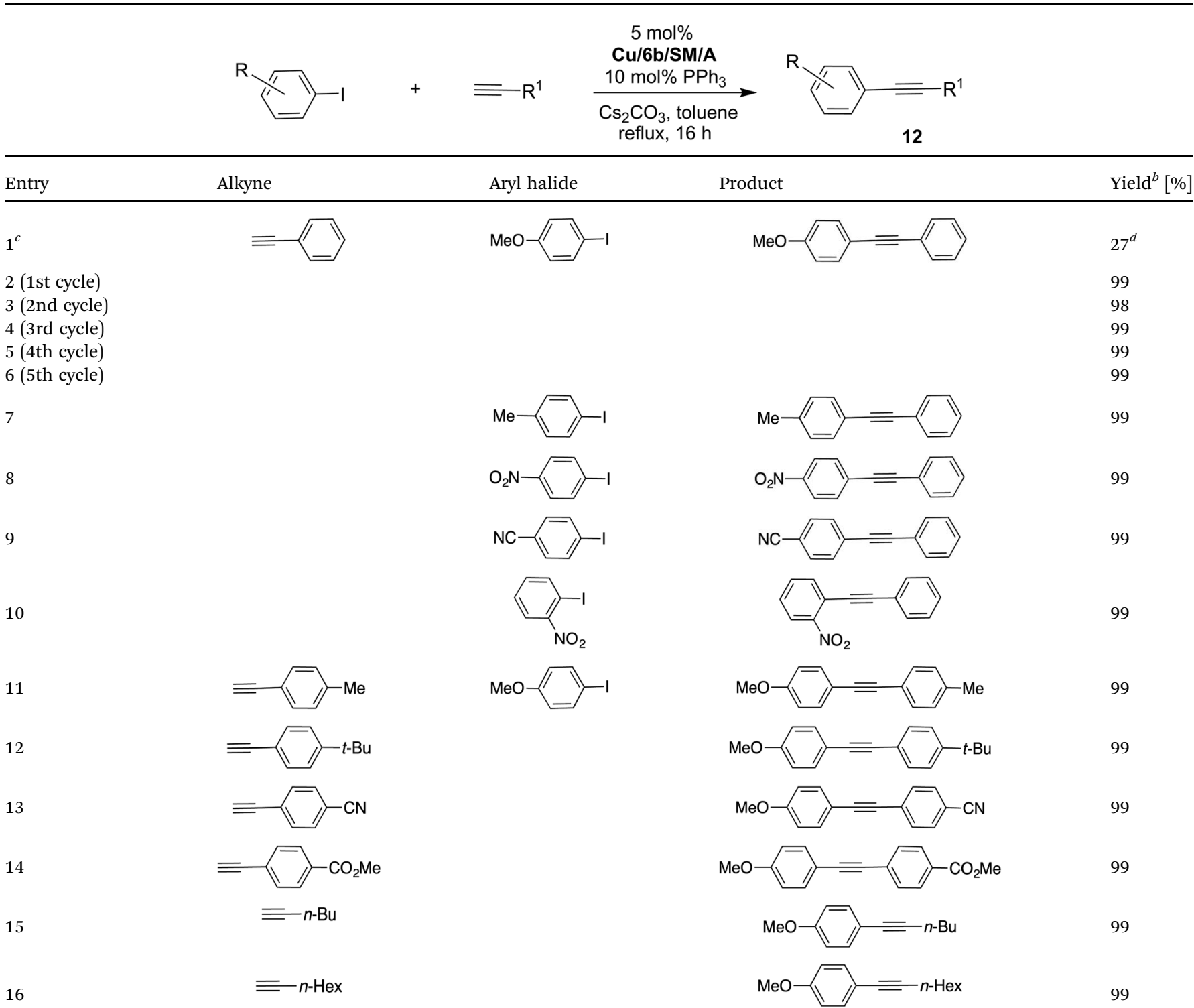

\footnotetext{
${ }^{a}$ Reaction conditions: $0.75 \mathrm{mmol}$ of the alkyne, $0.5 \mathrm{mmol}$ of the aryl halide, $1 \mathrm{mmol}$ of $\mathrm{Cs}_{2} \mathrm{CO}_{3}, 5 \mathrm{~mol} \% \mathrm{Cu} / \mathbf{6 b} / \mathbf{S M} / \mathbf{A}$ (calculated on the grafted complex) and $10 \mathrm{~mol} \%$ of $\mathrm{PPh}_{3}$ were refluxed in toluene $(2 \mathrm{~mL})$ under $\mathrm{Ar} .{ }^{b}$ The yield was determined by ${ }^{1} \mathrm{H}$ NMR spectroscopy of the crude product. ${ }^{c}$ The reaction was performed without $\mathrm{PPh}_{3} .{ }^{d} 77 \%$ conversion of the aryl halide was observed after $72 \mathrm{~h}$.
}

performed in the presence of cesium carbonate and $5 \mathrm{~mol} \%$ of $\mathbf{C u} / \mathbf{6 b} / \mathbf{S M} / \mathbf{A}$ (Table 5 , entry 1 ). The reaction proceeded slowly yielding the product of $\mathrm{C}-\mathrm{C}$ coupling in 27 and $77 \%$ yield after 16 and $72 \mathrm{~h}$, respectively. When $10 \mathrm{~mol} \%$ of $\mathrm{PPh}_{3}$ was added, the reaction afforded the target product 12 in $98 \%$ yield after $16 \mathrm{~h}$ of reflux. The reaction performed in the dark proceeds as well as in the daylight. This indicates that no photocatalytic process was observed under the studied conditions. To determine whether a non-supported copper catalyst could catalyse the reaction, a hot filtration test was performed (Fig. S40†). The filtered solution didn't show any catalytic activity that testified a heterogeneous catalytic process. The positive role of $\mathrm{PPh}_{3}$ in this heterogeneous reaction can stem from its influence on the structure of intermediate complexes involved in the catalytic cycle or its ability to reduce inactive $\mathrm{Cu}$ (II) complexes to copper(I) chelates. ${ }^{108}$

To prove that grafted phenanthroline complexes are true catalytic centres and clarify the role of the phen ligand, titaniasupported $\mathrm{Cu}(\mathrm{MeCN})_{4} \mathrm{PF}_{6}$ was prepared by the impregnation of $\mathrm{TiO}_{2}$ powder in $\mathrm{CH}_{2} \mathrm{Cl}_{2}$ solution of this complex at room temperature. This material and non-modified titanium support didn't promote the studied reaction indicating that titaniasupported $\mathbf{C u} / \mathbf{P p h e n}$ complexes are involved in the catalytic cycle.

Next, the reaction scope was explored. Coupling products 12 were obtained in near-quantitative yield starting from aryl halides with electron-donating or electron-withdrawing groups 


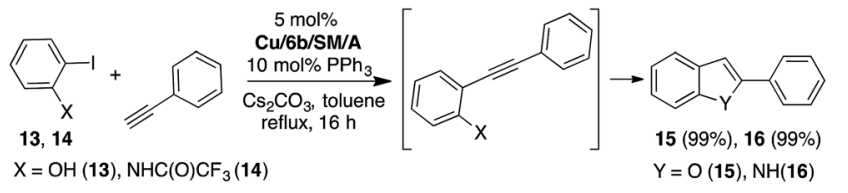

Scheme 6 Cascade reactions of iodides 13 and 14 with phenylacetylene.

including sterically bulky $o$-isomers. Phenylacetylene can also be replaced by different aliphatic or aromatic alkynes without any loss of selectivity and product yield (entries 11-16).

After the reaction proceeds to completion, the catalyst can be recovered by centrifugation, washing with $\mathrm{MeOH}$ and subsequent drying at $80{ }^{\circ} \mathrm{C}$ under reduced pressure. The catalytic performance of the recovered solid was explored in the reaction of $p$-iodoanisole with phenylacetylene. The catalyst was reused in five consecutive cycles retaining completely the selectivity and the product yield (entries 2-6). The recycled solids were also introduced in the reactions with different aryl iodides (entries 7-10) and showed the same catalytic efficiency as the catalyst $\mathbf{C u} / \mathbf{6 b} / \mathbf{S M} / \mathbf{A}$. When $o$-iodophenol (13) or $o$-iodo(trifluoroacetyl) aniline (14) was reacted with phenylacetylene, cascade catalytic reactions involving Sonogashira coupling and the addition of $\mathrm{N}-\mathrm{H}$ or $\mathrm{O}-\mathrm{H}$ bonds to the triple bond are observed to yield benzofuran 15 and indole 16 (Scheme 6). The cyclization products were obtained in quantitative yield.
It's worth noting that materials $\mathbf{3 b} / \mathbf{S G} / \mathbf{1 0}, \mathbf{3 b} / \mathbf{S G} / \mathbf{2 0}, \mathbf{1 b} / \mathbf{S M}$ and $\mathbf{2 b} / \mathbf{S M}$ based on copper complexes with one phen ligand also catalyse the reaction of phenylacetylene with $p$-iodoanisole. However, they are less convenient in practice due to a smaller number of catalytic centres as compared to $\mathbf{C u} / \mathbf{6 b} / \mathbf{S M} / \mathbf{A}$. In contrast, $\mathbf{4 b} / \mathbf{S M}$ and $\mathbf{5 b} / \mathbf{S M}$ prepared by grafting bis(Pphen) copper complexes $\mathbf{4 b}$ and $\mathbf{5 b}$ were inactive like their counterparts $4 \mathbf{a}$ and 5a, respectively, which were studied under homogeneous conditions. These results are in accordance with previous reports ${ }^{81}$ and can be explained by the slow dissociation kinetics of copper complexes bearing two phen ligands.

Huisgen 1,3-dipolar cycloaddition. Copper-catalysed alkyneazide cycloaddition is a novel synthesis paradigm having a remarkable practical and ecological impact and widely employed in the synthesis of many functional molecules including pharmaceuticals, dyes, sensors, and bioconjugates. ${ }^{109-116}$ This reaction allows delivery of sophisticated molecules or libraries of substituted 1,2,3-triazoles due to its selectivity, excellent functional compatibility, reliability and simplicity of experimental conditions. However, the separation of targeted molecules from resting copper by-products is still challenging and has a primordial importance for further development of this synthesis method..$^{33,35,41,117-120}$ In this regard, we have explored the alkyne-azide cycloaddition in the presence of the material $\mathbf{C u / 6 b / S M / A ~ ( T a b l e ~ 6 ) . ~ F i r s t , ~ t h e ~ r e a c - ~}$ tion conditions were optimized using the reaction of phenylacetylene with $p$-nitrobenzyl azide as a model reaction. The

Table 6 Huisgen cycloaddition catalysed by $\mathrm{Cu} / 6 \mathrm{~b} / \mathrm{SM} / \mathrm{A}^{a}$

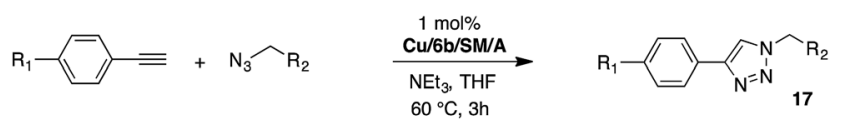

Entry

\footnotetext{
${ }^{a}$ Reaction conditions: $0.25 \mathrm{mmol}$ of the alkyne, $0.25 \mathrm{mmol}$ of the azide, $0.25 \mathrm{mmol}$ of $\mathrm{NEt}_{3}, 1 \mathrm{~mol} \%$ of $\mathbf{C u} / \mathbf{6 b} / \mathbf{S M} / \mathbf{A}$ (calculated on the grafted complex) in THF $(1 \mathrm{~mL})$ at $60{ }^{\circ} \mathrm{C}$ under Ar. ${ }^{b}$ Isolated yields. ${ }^{c}$ The reaction was performed with $5 \mathrm{~mol} \%$ of $\mathbf{C u} / \mathbf{6 b} / \mathbf{S M} / \mathbf{A}(\mathrm{calculated}$ on the grafted complex) for $1 \mathrm{~h}$.
} 
solvent was found to be a key parameter influencing the reaction rate. The cycloaddition product was not detected when the reaction was carried out in toluene or dichloromethane. Polar coordinating solvents like THF or DMF were required to obtain a complete conversion to 1,2,3-triazole, and in THF the reaction was rapid. When it was performed at $60{ }^{\circ} \mathrm{C}$ in the presence of triethylamine and $5 \mathrm{~mol} \%$ of $\mathbf{C u} / \mathbf{6 b} / \mathbf{S M} / \mathbf{A}$, the product was isolated in near-quantitative yield after $1 \mathrm{~h}$ of stirring (Table 6, entry 1). Complete conversion was also achieved employing 1 mol\% of the catalyst although the reaction time should be increased up to $3 \mathrm{~h}$ (entry 2 ). It is worth noting that the reaction was not observed under the studied conditions without the catalyst and in the presence of the non-modified $\mathrm{TiO}_{2}$ powder. A hot filtration test revealed that the cycloaddition proceeds as a heterogeneous process even when performed in the coordinating THF solvent and in the presence of triethylamine, which is a strong ligand for copper ions (Fig. S41†).

The reaction was successful and proceeded without complications with azides bearing benzyl and even alkyl residues (entries 3-5). The aromatic alkynes gave high yields of click products independent of whether electron-donor or electron-withdrawing substituents were present in the aromatic ring (entries 5-8).

Catalyst recovery and refining was straightforward. After completion of the reaction, the catalyst was isolated by centrifugation, washed with THF and introduced in the next cycle. Ten consecutive reactions of phenylacetylene with $p$-nitrobenzyl azide

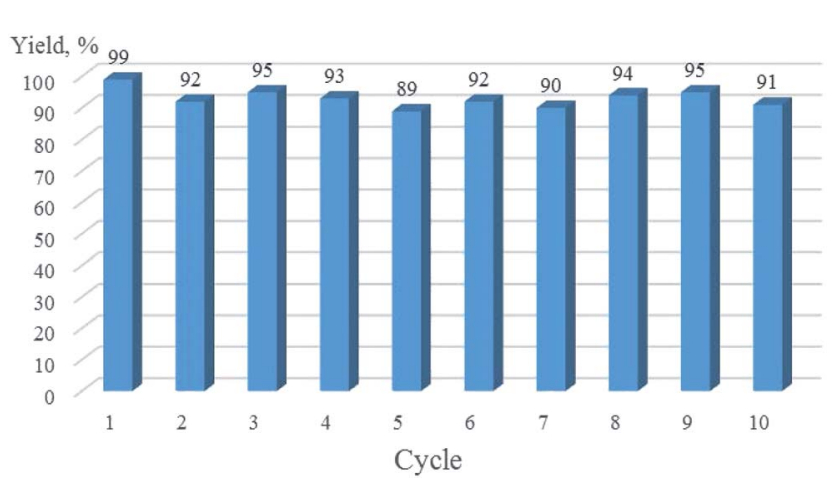

Fig. 6 Recycling of $\mathrm{Cu} / 6 \mathrm{~b} / \mathrm{SM} / \mathrm{A}$ in the Huisgen cycloaddition of phenylacetylene with $p$-nitrobenzyl azide (Table 6, entry 1). were carried out giving the target 1,2,3-triazole in comparable yields (90-98\%) (Fig. 6). The content of resting copper derivatives in the final products was determined by using the ICP-OES technique. The average value of copper content was found to be $48 \mathrm{ppm}$ and $15 \mathrm{ppm}$ for the Sonogashira coupling (Table 5, entry 2) and the Huisgen cycloaddition (Table 6, entry 1) reactions, respectively, which is among the lowest values reported for heterogeneous copper catalysts. ${ }^{23,121-127}$

The morphology of recovered catalysts was also investigated by using SEM microphotography of the solid recovered after the Sonogashira-type coupling performed in toluene in the presence of $\mathrm{PPh}_{3}$ and the strong $\mathrm{Cs}_{2} \mathrm{CO}_{3}$ base. As seen in Fig. 7, the morphology of $\mathbf{C u} / \mathbf{6 b} / \mathbf{S M} / \mathrm{A}$ remains intact after completion of the reaction and the powder is composed of uniform agglomerates of primary nanoparticles.

\section{Conclusions}

In the present work, different strategies for the covalent immobilization of copper complexes with phen ligands functionalized by phosphonate groups (Pphen) were systematically explored. The reported SG methods for the preparation of titania-supported transition metal complexes were compared with the SM of hydrated mesoporous titania that we have synthesized recently. The resulting hybrid materials were characterized as both bulk solids and at the molecular level by using different physicochemical methods including elemental analysis, infrared spectroscopy, nitrogen sorption isotherms, and SEM microphotography.

Immobilization of labile heteroleptic copper(I) complexes with Pphen ligands is accompanied by a partial removal of metal ions whatever experimental procedure was used for the covalent linkage of these complexes to $\mathrm{TiO}_{2}$ supports. This drawback can be overcome by using the stepwise method involving the immobilization of Pphen-Si ligands and their consecutive complexation with copper(I) ions. The most porous material $\mathbf{C u}$ / 6b/SM/A in which the Pphen ligand is linked to the surface by a single phosphonate group located at the 3-position of the phenanthroline backbone and coordinated to copper(I) ions was prepared by the post-synthesis modification of hydrated mesoporous $\mathrm{TiO}_{2}\left(S_{\mathrm{BET}}=650 \mathrm{~m}^{2} \mathrm{~g}^{-1}\right)$. This material exhibits a BET
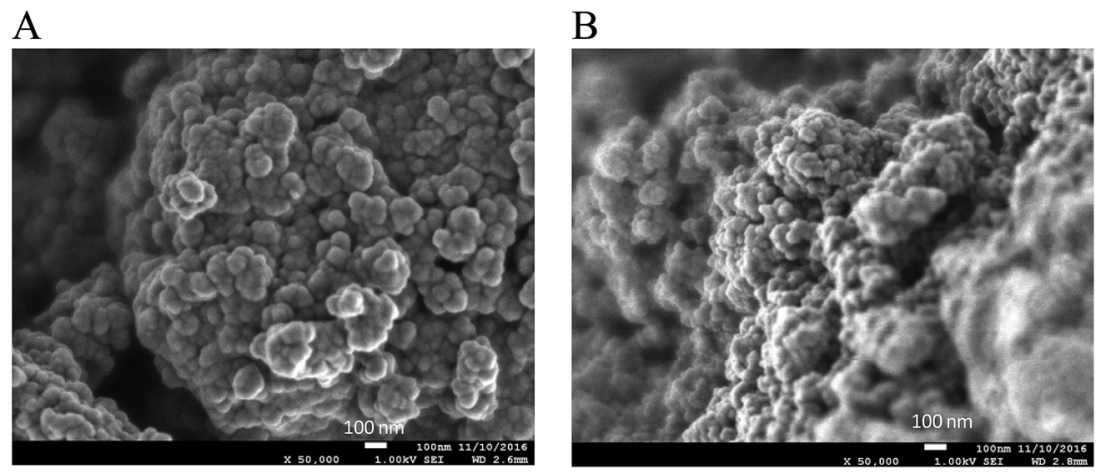

Fig. 7 SEM microphotographs of solid Cu/6b/SM/A (A), and the recycled catalyst after Sonogashira coupling (B). The images were obtained using samples prepared by the dispersion of the materials on a conductive carbon tape and carbon coating $(8 \mathrm{~nm})$. 
surface area of $246 \mathrm{~m}^{2} \mathrm{~g}^{-1}$, contains $0.57 \mathrm{mmol}$ of the grafted complex per gram of the solid and benefits from the high thermal and chemical robustness, nanosized morphology, mesoporosity and spatial separation of catalytic sites.

The excellent catalytic performance of $\mathbf{C u} / \mathbf{6 b} / \mathbf{S M} / \mathbf{A}$ in the Sonogashira-type coupling and Huisgen 1,3-dipolar cycloaddition was also demonstrated. Fairly low catalyst loading, simple recovery and reuse of the solid were achieved in both studied reactions proceeding through principally different reaction pathways. This catalytic versatility of the copper catalyst is highly desirable for sustainable chemistry but still rarely reported owing to the challenge in the preparation of robust catalysts applicable for a wide range of experimental conditions. Our ongoing work focuses on the screening of catalytic reactions promoted by $\mathbf{C u} / \mathbf{6 b}$ / SM/A. This work also paves the way towards cost-effective heterogenized transition metal catalysts prepared by grafting of metal complexes decorated by phosphonate anchoring groups onto the surface of mesoporous $\mathrm{TiO}_{2}$ that we have prepared recently by the non-templating sol-gel process.

\section{Acknowledgements}

Myriam Heydel, Fanny Picquet and Marcel Soustelle are warmly acknowledged for their technical support. The authors are very grateful to Remi Chassagnon for the cooperation in TEM studies and helpful discussions. A. Yu. Mitrofanov thanks the Russian Foundation for Basic Research (grant No. 16-33-60207) for the financial support and the French government for the PhD fellowship. Financial support from the CNRS and the Burgundy Region (PARI IME SMT8 and PARI II CDEA programs) is also acknowledged. This work was carried out in the frame of the International Associated French-Russian (LIA) Laboratory of Macrocycle Systems and Related Materials (LAMREM) of CNRS and RAS.

\section{References}

1 G. Evano, N. Blanchard and M. Toumi, Chem. Rev., 2008, 108, 3054-3131.

2 Copper-mediated Cross-coupling Reactions, ed. G. Evano and N. Blanchard, Wiley, Hoboken, 2013, p. 840.

3 P. Subramanian, G. C. Rudolf and K. P. Kaliappan, Chem.Asian J., 2016, 11, 168-192.

$4 \mathrm{C}-\mathrm{H}$ and $\mathrm{C}-\mathrm{X}$ Bond Functionalization: Transition Metal Mediation, ed. X. Ribas, RSC Publishing, Cambrige, 2013, p. 350.

5 F. Monnier and M. Taillefer, in Amination and Formation of sp2 $C-N$ Bonds, ed. M. Taillefer and D. Ma, Springer, Berlin, Heidelberg, 2013, pp. 173-204.

6 A. P. Jadhav, D. Ray, V. U. B. Rao and R. P. Singh, Eur. J. Org. Chem., 2016, 2369-2382.

7 C. Maaliki, E. Thiery and J. Thibonnet, Eur. J. Org. Chem., 2016, 209-228.

8 I. P. Beletskaya and A. V. Cheprakov, Organometallics, 2012, 31, 7753-7808.

9 Y. Shimizu and M. Kanai, Tetrahedron Lett., 2014, 55, 37273737.
10 V. Castro, H. Rodríguez and F. Albericio, ACS Comb. Sci., 2016, 18, 1-14.

11 A. S. Hay, J. Org. Chem., 1962, 27, 3320-3321.

12 G. W. Kabalka, L. Wang and R. M. Pagni, Synlett, 2001, 108110.

13 J. S. Yadav, B. V. S. Reddy, K. B. Reddy, K. U. Gayathri and A. R. Prasad, Tetrahedron Lett., 2003, 44, 6493-6496.

14 T. F. Knöpfel and E. M. Carreira, J. Am. Chem. Soc., 2003, 125, 6054-6055.

15 K. Kamata, S. Yamaguchi, M. Kotani, K. Yamaguchi and N. Mizuno, Angew. Chem., Int. Ed., 2008, 13, 2407-2410.

16 Copper in drinking-water. Background document for development of WHO guidelines for drinking-water quality, 2004.

17 V. Balaram, Trends Anal. Chem., 2016, 80, 83-95.

18 M. B. Gawande, A. Goswami, F.-X. Felpin, T. Asefa, X. Huang, R. Silva, X. Zou, R. Zboril and R. S. Varma, Chem. Rev., 2016, 116, 3722-3811.

19 M. Keller, M. Ianchuk, S. Ladeira, M. Taillefer, A. M. Caminade, J. P. Majoral and A. Ouali, Eur. J. Org. Chem., 2012, 1056-1062.

20 C.-K. Chen, Y.-W. Chen, C.-H. Lin, H.-P. Lin and C.-F. Lee, Chem. Commun., 2010, 46, 282-284.

21 A. Coelho, P. Diz, O. Caamaño and E. Sotelo, Adv. Synth. Catal., 2010, 352, 1179-1192.

22 R. Arundhathi, D. C. Kumar and B. Sreedhar, Eur. J. Org. Chem., 2010, 3621-3630.

23 K. R. Reddy, N. S. Kumar, B. Sreedhar and M. L. Kantam, J. Mol. Catal. A: Chem., 2006, 252, 136-141.

24 M. L. Kantam, B. P. C. Rao, B. M. Choudary and R. S. Reddy, Synlett, 2006, 2195-2198.

25 S. M. Auer, M. Schneider and A. Baiker, J. Chem. Soc., Chem. Commun., 1995, 2057-2058.

26 P. Yu, Y. Zhou, Y. Yang and R. Tang, RSC Adv., 2016, 6, 65403-65411.

27 B. M. Choudary, C. Sridhar, M. L. Kantam and B. Sreedhar, Tetrahedron Lett., 2004, 45, 7319-7321.

28 B. M. Choudary, C. Sridhar, M. L. Kantam, G. T. Venkanna and B. Sreedhar, J. Am. Chem. Soc., 2005, 127, 9948-9949.

29 F. Boccuzzi, G. Martra, C. P. Papalia and N. Ravasio, J. Catal., 1999, 184, 327-334.

30 M. P. Pachamuthu, S. Karthikeyan, R. Maheswari, A. F. Lee and A. Ramanathan, Appl. Surf. Sci., 2017, 393, 67-73.

31 F. Zaccheria, N. Ravasio, A. Fusi, M. Rodondi and R. Psaro, Adv. Synth. Catal., 2005, 347, 1267-1272.

32 F. Zaccheria, N. Ravasio, R. Psaro and A. Fusi, Chem.-Eur. J., 2006, 12, 6426-6431.

33 I. S. Park, M. S. Kwon, Y. Kim, J. S. Lee and J. Park, Org. Lett., 2008, 10, 497-500.

34 S. Bhadra, B. Sreedhar and B. C. Ranu, Adv. Synth. Catal., 2009, 351, 2369-2378.

35 B. H. Lipshutz and B. R. Taft, Angew. Chem., Int. Ed., 2006, 45, 8235-8238.

36 T. Oishi, K. Yamaguchi and N. Mizuno, ACS Catal., 2011, 1, 1351-1354.

37 P. Tepmatee and P. Siriphannon, Bull. Pol. Acad. Sci.: Tech. Sci., 2016, 64, 553-560. 
38 M. Bhardwaj, M. Kour and S. Paul, RSC Adv., 2016, 6, 9960499614.

39 W. Cao, H. Zhang and Y. Yuan, Catal. Lett., 2003, 91, 243246.

40 W. Chen, Y. Zhang, L. Zhu, J. Lan, R. Xie and J. You, J. Am. Chem. Soc., 2007, 129, 13879-13886.

41 A. Megia-Fernandez, M. Ortega-Muñoz, J. Lopez-Jaramillo, F. Hernandez-Mateo and F. Santoyo-Gonzalez, Adv. Synth. Catal., 2010, 352, 3306-3320.

42 D. R. Godhani, H. D. Nakum, D. K. Parmar, J. P. Mehta and N. C. Desai, Inorg. Chem. Commun., 2016, 72, 105-116.

43 J.-C. Wang, Y.-H. Hu, G.-J. Chen and Y.-B. Dong, Chem. Commun., 2016, 52, 13116-13119.

44 S. Behrouz and M. N. S. Rad, ChemInform, 2016, 47, DOI: 10.1002/chin.201620132.

45 T. Miao and L. Wang, Synthesis, 2008, 363-368.

46 P. Li and L. Wang, Tetrahedron, 2007, 63, 5455-5459.

47 L. Wang, P. Li and L. Zhang, Lett. Org. Chem., 2006, 3, 282285.

48 M. Islam, S. Mondal, P. Mondal, A. S. Roy, K. Tuhina, M. Mobarok, S. Paul, N. Salam and D. Hossain, Catal. Lett., 2011, 141, 1171-1181.

49 C. Queffelec, M. Petit, P. Janvier, D. A. Knight and B. Bujoli, Chem. Rev., 2012, 112, 3777-3807.

50 G. Guerrero, J. G. Alauzun, M. Granier, D. Laurencin and P. H. Mutin, Dalton Trans., 2013, 42, 12569-12585.

51 Y.-P. Zhu, T.-Z. Ren and Z.-Y. Yuan, Catal. Sci. Technol., 2015, 5, 4258-4279.

52 P. Bhanja and A. Bhaumik, ChemCatChem, 2016, 8, 16071616.

53 C. Maillet, P. Janvier, M. Pipelier, T. Praveen, Y. Andres and B. Bujoli, Chem. Mater., 2001, 13, 2879-2884.

54 A. Vioux, J. Le Bideau, P. H. Mutin and D. Leclercq, Top. Curr. Chem., 2004, 232, 145-174.

55 Y.-P. Zhu, T.-Y. Ma, Y.-L. Liu, T.-Z. Ren and Z.-Y. Yuan, Inorg. Chem. Front., 2014, 1, 360-383.

56 G. Guerrero, P. H. Mutin, E. Framery and A. Vioux, New J. Chem., 2008, 32, 1519-1525.

57 C. Maillet, P. Janvier, M.-J. Bertrand, T. Praveen and B. Bujoli, Eur. J. Org. Chem., 2002, 1685-1689.

58 T. L. Schull, L. Henley, J. R. Deschamps, R. J. Butcher, D. P. Maher, C. A. Klug, K. Swider-Lyons, W. J. Dressick, B. Bujoli, A. E. Greenwood, L. K. B. Congiardo and D. A. Knight, Organometallics, 2007, 26, 2272-2276.

59 R. Gujadhur, D. Venkataraman and J. T. Kintigh, Tetrahedron Lett., 2001, 42, 4791-4793.

60 D. Tzalis and Y. Tor, Tetrahedron Lett., 1995, 36, 6017-6020.

61 C. Dietrich-Buchecker, B. Colasson, D. Jouvenot and J.-P. Sauvage, Chem.-Eur. J., 2005, 11, 4374-4386.

62 T. Ishiyama, M. Murata and N. Miyaura, J. Org. Chem., 1995, 60, 7508-7510.

63 N. N. Makukhin, PhD, Lomonosov Moscow State University, 2013.

64 A. Mitrofanov, A. Bessmertnykh Lemeune, C. Stern, R. Guilard, N. Gulyukina and I. Beletskaya, Synthesis, 2012, 44, 3805-3810.
65 A. Mitrofanov, M. Manowong, Y. Rousselin, S. Brandes, R. Guilard, A. Bessmertnykh-Lemeune, P. Chen, K. M. Kadish, N. Goulioukina and I. Beletskaya, Eur. J. Inorg. Chem., 2014, 3370-3386.

66 H. E. Gottlieb, V. Kotlyar and A. Nudelman, J. Org. Chem., 1997, 62, 7512-7515.

67 G. R. Fulmer, A. J. M. Miller, N. H. Sherden, H. E. Gottlieb, A. Nudelman, B. M. Stoltz, J. E. Bercaw and K. I. Goldberg, Organometallics, 2010, 29, 2176-2179.

68 S. Brunauer, P. H. Emmett and E. Teller, J. Am. Chem. Soc., 1938, 60, 309-319.

69 E. P. Barrett, L. G. Joyner and P. P. Halenda, J. Am. Chem. Soc., 1951, 73, 373-380.

70 S. B. Park and H. Alper, Chem. Commun., 2004, 1306-1307.

71 S. Wang, M. Wang, L. Wang, B. Wang, P. Li and J. Yang, Tetrahedron, 2011, 67, 4800-4806.

72 H. Peng, Y.-Q. Chen, S.-L. Mao, Y.-X. Pi, Y. Chen, Z.-Y. Lian, T. Meng, S.-H. Liu and G.-A. Yu, Org. Biomol. Chem., 2014, 12, 6944-6952.

73 C. J. Wenthur, R. Morrison, A. S. Felts, K. A. Smith, J. L. Engers, F. W. Byers, J. S. Daniels, K. A. Emmitte, P. J. Conn and C. W. Lindsley, J. Med. Chem., 2013, 56, 5208-5212.

74 S. Kankala, R. Vadde and C. S. Vasam, Org. Biomol. Chem., 2011, 9, 7869-7876.

75 H. Kim and P. H. Lee, Adv. Synth. Catal., 2009, 351, 28272832.

76 S. S. E. Ghodsinia, B. Akhlaghinia and R. Jahanshahi, RSC Adv., 2016, 6, 63613-63623.

77 R. Jahanshahi and B. Akhlaghinia, $R S C A d v$., 2016, 6, 29210-29219.

78 S. Ladouceur, A. M. Soliman and E. Zysman-Colman, Synthesis, 2011, 3604-3611.

79 H. Xu and Z. Sun, Adv. Synth. Catal., 2016, 358, 1736-1740.

80 O. I. Artyushin, D. V. Vorob'eva, T. P. Vasil'eva, S. N. Osipov, G.-V. Roschenthaler and I. L. Odinets, Heteroat. Chem., 2008, 19, 293-300.

81 A. Y. Mitrofanov, A. G. Bessmertnykh-Lemeune and I. P. Beletskaya, Inorg. Chim. Acta, 2015, 431, 297-301.

82 P. M. DiGiacomo and M. B. Dines, US 4299943, 1981.

83 G. Guerrero, P. H. Mutin and A. Vioux, Chem. Mater., 2001, 13, 4367-4373.

84 M. Mehring, V. Lafond, P. H. Mutin and A. Vioux, J. Sol-Gel Sci. Technol., 2003, 26, 99-102.

85 N. R. E. Radwan, M. Mokhtar and G. A. El-Shobaky, J. Therm. Anal. Calorim., 2003, 71, 977-986.

86 G. Li, L. Li, J. Boerio-Goates and B. F. Woodfield, J. Am. Chem. Soc., 2005, 127, 8659-8666.

87 N. Nakayama and T. Hayashi, Colloids Surf., A, 2008, 317, 543-550.

88 T. P. Gerasimova and S. A. Katsyuba, Dalton Trans., 2013, 42, 1787-1797.

89 B. Ackerman, T. A. Jordan, C. R. Eddy and D. Swern, J. Am. Chem. Soc., 1956, 78, 4444-4447.

90 P. Persson, E. Laiti and L.-O. Öhman, J. Colloid Interface Sci., 1997, 190, 341-349. 
91 J. Randon, P. Blanc and R. Paterson, J. Membr. Sci., 1995, 98, 119-129.

92 A. Raman, R. Quiñones, L. Barriger, R. Eastman, A. Parsi and E. S. Gawalt, Langmuir, 2010, 26, 1747-1754.

93 R. J. H. Clark, C. D. Flint and A. J. Hempleman, Spectrochim. Acta, Part A, 1987, 43, 805-816.

94 D. Geldof, M. Tassi, R. Carleer, P. Adriaensens, A. Roevens, V. Meynen and F. Blockhuys, Surf. Sci., 2017, 655, 31-38.

95 G. Guerrero, P. H. Mutin and A. Vioux, Chem. Mater., 2000, 12, 1268-1272.

96 P. H. Mutin, V. Lafond, A. F. Popa, M. Granier, L. Markey and A. Dereux, Chem. Mater., 2004, 16, 5670-5675.

97 G. Murphy, C. Murphy, B. Murphy and B. Hathaway, J. Chem. Soc., Dalton Trans., 1997, 2653-2660.

98 Y. Yamada, H. Sakurai, Y. Miyashita, K. Fujisawa and K.-i. Okamoto, Polyhedron, 2002, 21, 2143-2147.

99 R. Chinchilla and C. Najera, Chem. Soc. Rev., 2011, 40, 50845121.

100 M. Bakherad, Appl. Organomet. Chem., 2013, 27, 125-140.

101 A. R. Hajipour and F. Mohammadsaleh, Tetrahedron Lett., 2014, 55, 3459-3462.

102 J. Moegling, A. D. Benischke, J. M. Hammann, N. A. Veprek, F. Zoller, B. Rendenbach, A. Hoffmann, H. Sievers, M. Schuster, P. Knochel and S. Herres-Pawlis, Eur. J. Org. Chem., 2015, 7475-7483.

103 N. P. Probst, B. Deprez and N. Willand, Tetrahedron Lett., 2016, 57, 1066-1070.

104 B. W. T. Gruijters, M. A. C. Broeren, F. L. van Delft, R. P. Sijbesma, P. H. H. Hermkens and F. P. J. T. Rutjes, Org. Lett., 2006, 8, 3163-3166.

105 A. Biffis, E. Scattolin, N. Ravasio and F. Zaccheria, Tetrahedron Lett., 2007, 48, 8761-8764.

106 Z. Wang, L. Wang and P. Li, Synthesis, 2008, 1367-1372.

107 A. R. Hajipour, S. M. Hosseini and F. Mohammadsaleh, New J. Chem., 2016, 40, 6939-6945.

108 L.-j. Bai, W.-x. Wang, M.-h. Wang, J.-m. Sun and H. Chen, Chin. J. Polym. Sci., 2015, 33, 1260-1270.

109 Click Chemistry for Biotechnology and Materials Science, ed. J. Lahann, Wiley, Chichester, 2009, p. 144.
110 V. Castro, H. Rodriguez and F. Albericio, ACS Comb. Sci., 2016, 18, 1-14.

111 J.-P. Meyer, P. Adumeau, J. S. Lewis and B. M. Zeglis, Bioconjugate Chem., 2016, 27, 2791-2807.

112 X.-P. He, Y.-L. Zeng, Y. Zang, J. Li, R. A. Field and G.-R. Chen, Carbohydr. Res., 2016, 429, 1-22.

113 K. Kacprzak, I. Skiera, M. Piasecka and Z. Paryzek, Chem. Rev., 2016, 116, 5689-5743.

114 V. K. Tiwari, B. B. Mishra, K. B. Mishra, N. Mishra, A. S. Singh and X. Chen, Chem. Rev., 2016, 116, 3086-3240.

115 C. Wang, D. Ikhlef, S. Kahlal, J.-Y. Saillard and D. Astruc, Coord. Chem. Rev., 2016, 316, 1-20.

116 M. S. Singh, S. Chowdhury and S. Koley, Tetrahedron, 2016, 72, 5257-5283.

117 C. Girard, E. Önen, M. Aufort, S. Beauvière, E. Samson and J. Herscovici, Org. Lett., 2006, 8, 1689-1692.

118 I. Jlalia, H. Elamari, F. Meganem, J. Herscovici and C. Girard, Tetrahedron Lett., 2008, 49, 6756-6758.

119 P. Li, L. Wang and Y. Zhang, Tetrahedron, 2008, 64, 1082510830.

120 H. Sharghi, R. Khalifeh and M. M. Doroodmand, Adv. Synth. Catal., 2009, 351, 207-218.

121 M. Ercoli, A. Fusi, R. Psaro, N. Ravasio and F. Zaccheria, J. Mol. Catal. A: Chem., 2003, 204-205, 729-735.

122 P. R. Likhar, S. Roy, M. Roy, M. L. Kantam and R. L. De, J. Mol. Catal. A: Chem., 2007, 271, 57-62.

123 S. Benyahya, F. Monnier, M. Taillefer, M. W. C. Man, C. Bied and F. Ouazzani, Adv. Synth. Catal., 2008, 350, 2205-2208.

124 S. Benyahya, F. Monnier, M. Wong Chi Man, C. Bied, F. Ouazzani and M. Taillefer, Green Chem., 2009, 11, 1121-1123.

125 W. Mo, H. Liu, H. Xiong, M. Li and G. Li, Appl. Catal., A, 2007, 333, 172-176.

126 P. Ling, D. Li and X. Wang, J. Mol. Catal. A: Chem., 2012, 357, 112-116.

127 P. Zhang, J. Yuan, H. Li, X. Liu, X. Xu, M. Antonietti and Y. Wang, RSC Adv., 2013, 3, 1890-1895. 